\title{
Multikinase Abl/DDR/Src Inhibition Produces Optimal Effects for Tyrosine Kinase Inhibition in Neurodegeneration
}

\author{
Alan J. Fowler ${ }^{1,2} \cdot$ Michaeline Hebron $^{1} \cdot$ Alexander A. Missner ${ }^{1} \cdot$ Ruchong Wang $^{1} \cdot$ Xiaokong Gao $^{1}$. \\ Bahjat T. Kurd-Misto ${ }^{1}$ Xiaoguang Liu ${ }^{1}$. Charbel E.-H. Moussa ${ }^{1,3}$
}

Published online: 27 March 2019

(c) The Author(s) 2019

\begin{abstract}
Background and objectives Inhibition of Abelson (Abl) tyrosine kinase as a therapeutic target has been gaining attention in neurodegeneration. Post-mortem Alzheimer's and Parkinson's disease brains show that the levels of several other tyrosine kinases, including Discoidin Domain Receptors (DDR1/2) are elevated. Knockdown of these tyrosine kinases with shRNA reduces neurotoxic proteins, including alpha-synuclein, beta-amyloid and tau.

Methods Direct profiling of the pharmacokinetics of multi-kinase inhibitors Nilotinib, Bosutinib, Bafetinib, Radotinib and LCB-03-0110 shows differential levels of brain penetration but the ability of these agents to reduce toxic proteins is independent of brain concentration and selectivity to Abl.

Results Our results indicate that the effective dose of Nilotinib has the lowest plasma:brain ratio (1\%) followed by Bosutinib and Radotinib (5\%), Bafetinib (12\%) and LCB-03-0110 (12\%). However, similar doses of multi-kinase Abl/DDR inhibitor Nilotinib, DDR/Src inhibitor LCB-03-0110 and Abl/Src inhibitor Bosutinib were much more effective than the more selective Abl inhibitors Radotinib and Bafetinib. Taken together, these data suggest that a multi-kinase target that includes Abl and other tyrosine kinases (DDRs, and Src) may offer more advantages alleviating neurodegenerative pathologies than the absolute CNS drug concentration and selectivity to Abl.
\end{abstract}

Conclusion DDRs and Src are other potential co-targets with Abl in neurodegeneration.

Electronic supplementary material The online version of this article (https://doi.org/10.1007/s40268-019-0266-z) contains supplementary material, which is available to authorized users.

Charbel E.-H. Moussa

Cem46@georgetown.edu

Alan J. Fowler

ajf115@georgetown.edu

Alexander A. Missner

am3212@gerogetown.edu

Ruchong Wang

rw96275@uga.edu

Xiaokong Gao

gaox@upstate.edu

Bahjat T. Kurd-Misto

tkmisto@gmail.com

Xiaoguang Liu

x1371@georgetown.edu
1 Department of Neurology, Laboratory for Dementia and Parkinsonism, Translational Neurotherapeutics Program, Parkinson's Foundation Center of Excellence, Georgetown University Medical Center, Washington, DC, USA

2 Interdisciplinary Program in Neuroscience, Georgetown University Medical Center, Washington, DC, USA

3 Department of Neurology, Laboratory for Dementia and Parkinsonism, Translational Neurotherapeutics Program, Parkinson's Foundation Center of Excellence, Lewy Body Dementia Research Center of Excellence, Georgetown University Medical Center, Room 203C, Building D, 4000 Reservoir Road, NW, Washington, DC 20057, USA 


\section{Key Points}

The ability of these multi-kinase tyrosine kinase inhibitors to alleviate neurodegenerative pathologies is independent of their brain concentration and their selectivity to abelson.

Multi-kinase targeting of abelson, discoidin domain receptor, and Src may offer more advantages in alleviating neurodegenerative pathologies.

\section{Background}

Over-expression and activation of some tyrosine kinases (TKs) may be pathological features in neurodegeneration [1-8], Abelson (Abl) is a non-receptor TK, which is upregulated in post-mortem Alzheimer's disease (AD) and Parkinson's disease (PD) brains and in animal models of neurodegeneration $[1,4,5,7-12]$. Abelson has several neuronal functions, including cytoskeleton regulation, cell-cycle regulation, and apoptosis [13-15]. Discoidin domain receptors 1 and 2 (DDR1/2) are members of the receptor TK family and share $89 \%$ homology in their kinase domains [16] and are upregulated in post-mortem $\mathrm{PD}$ and AD brains [2]. Discoidin domain receptors, which are widely expressed in neurons and glia, modulate cell division and may regulate the number of myeloid-derived glial cells [2, 16-19]. We previously reported that short hairpin RNA (shRNA) knockdown of DDRs significantly reduces amyloid- $\beta$ (A $\beta)$ and tau in transfected cells [2]. Additionally, specific knockdown of DDR $1 / 2$ reduces $A \beta_{42}$, tau, and $\alpha$-synuclein ( $\alpha$-syn) and alters Triggering Receptor Expressed on Myeloid (TREM)-2 signaling in AD and PD animal models [2]. The data indicate that several TKs may be involved in the pathogenesis of neurodegenerative diseases (NDs).

Autophagic dysfunction is a pathological feature of neurodegeneration, including AD and PD [20-27]. Autophagic defects in neurodegeneration are partly characterized by accumulation of un-degraded autophagic vacuoles in the cytosol of surviving neurons [20, 26-28]. We previously demonstrated that pre-lysosomal vacuoles accumulate in the substantia nigra of patients with PD and not in control subjects [5, 20]. Subcellular fractionation of post-mortem brains revealed that $\alpha$-syn in PD $[5,20]$ and A $\beta$ and tau in AD [29] accumulate in pre-lysosomal vacuoles, suggesting defects in autophagic flux and accumulation of toxic proteins in undigested autophagic vacuoles.

Inhibition of TKs has been established as a strategy partly to stimulate autophagy as a maintenance therapy in cancers $[30,31]$. Two second-generation tyrosine kinase inhibitors (TKIs), nilotinib (Tasigna, AMN107, Novartis, Basel,
Basel-Stadt, Switzerland) and bosutinib (Bosulif, SKI-606, Pfizer, New York City, New York, USA), are US Food and Drug Administration approved for chronic myelogenous leukemia [32, 33]. We demonstrated that nilotinib, a preferential breakpoint cluster region-Abl inhibitor, penetrates the blood-brain barrier (BBB), improves motor and cognitive symptoms, attenuates neuroinflammation, and reduces neurotoxic proteins via autophagy in animal models of PD and AD [3-5, 29, 34-37]. Additionally, nilotinib treatment may improve motor and cognitive symptoms in patients with PD and dementia with Lewy bodies [38]. Nilotinib also potently inhibits DDR1/2 [39, 40] and may be selective for platelet-derived growth factor receptors (PDGFRs)- $\alpha / \beta$ $[41,42]$. Platelet-derived growth factor receptors- $\alpha / \beta$ are receptor TKs that play an important role in neurodegeneration [43] and they regulate BBB pericytes [44-46]. Plateletderived growth factors promote proliferation, survival, and migration of cells of mesenchymal origin and their dysfunction is implicated in several neurological conditions [47]. Bosutinib, a dual Src/Abl inhibitor, like nilotinib, promotes autophagic clearance of $\mathrm{A} \beta, \alpha$-syn, and tau and reduces inflammation in gene-transfer and transgenic animal models of AD and PD [3, 35, 37, 48]. Similar to nilotinib, bosutinib potently inhibits Abl [49], as well as another structurally homologous TK Src [50] but seems to display no selectivity to PDGFR $\alpha / \beta$ [42]. Furthermore, bafetinib (INNO-406) is a dual breakpoint cluster region-Abl/Lyn second-generation TKI that penetrates the brain, inhibits $\mathrm{Abl}$, and protects dopaminergic neurons in 1-methyl-4-phenyl-1,2,3,6-tetrahydropyridine (MPTP) mouse models [51]. More recently, the Abl inhibitor radotinib hydrochloride (Supect, Il-Yang Pharmaceutical Co., Ltd, Seoul, Rep. of Korea) was reported to penetrate the brain and inhibit $\mathrm{Abl}$ in a pre-formed fibril model of $\alpha$-synucleinopathy [52].

The overlap in TK selectivity and the multi-target properties of TKIs suggest that several TKs may be concurrently involved in mediating the effects of these drugs in neurodegeneration. To delineate the effects of nilotinib, bosutinib, radotinib, and bafetinib on neurodegenerative pathologies, we studied the pharmacokinetics and pharmacodynamics of these drugs using daily intraperitoneal (IP) injections at doses of $5-10 \mathrm{mg} / \mathrm{kg}$, which were the effective doses we observed in neurodegeneration models of up to 3 consecutive weeks of treatment. Human post-mortem brain tissues show upregulation of Abl, DDRs, and PDGFRs in AD and PD brains and shRNA knockdown of these kinases results in the reduction of neurotoxic proteins in cellular models. In this work, we also show (3-(2-(3-(morpholinomethyl)phenyl)thieno[3,2-b]pyridin-7-ylamino)phenol known as LCB03-0110 (LCB), which is a potent small-molecule inhibitor against the DDR family and Src TK family [53], as a highly effective agent at reducing neurotoxic protein levels at lower doses than Abl inhibitors. The results suggest that TKIs with 
broad multi-kinase Abl/DDR/Src inhibition at low doses have optimal effects in the central nervous system (CNS).

\section{Methods}

\subsection{Human Brain Immunohistochemistry}

Autopsies of human AD hippocampal and PD midbrain regions were collected from 12 patients and compared to 11 age-matched control subjects obtained from the Johns Hopkins University brain bank. Complete demographics, disease stage and diagnosis, post-mortem autopsy, age, and sex were previously published in Hebron et al. [5] and Lonskaya et al. [3]. For immunohistochemistry, 5- $\mu \mathrm{m}$-thick paraffin-embedded brain slices were de-paraffinized in xylenes for $2 \times 5 \mathrm{~min}$ and sequential ethanol concentration, blocked for $1 \mathrm{~h}$ in $10 \%$ horse serum, and incubated overnight with primary antibodies at $4{ }^{\circ} \mathrm{C}$. After $3 \times 10$ min washes in $1 \times$ phosphate buffered saline, the samples were incubated with the secondary antibodies for $1 \mathrm{~h}$ at room temperature (RT), washed for $3 \times 10 \mathrm{~min}$ in $1 \times$ phosphate buffered saline and 3,3'-diaminobenzidine stained. c-Abl was probed with a (1:500) c-Abl rabbit polyclonal antibody (Cat. \#PA1-46467, Invitrogen Inc., Carlsbad, CA, USA). PDGFR $\alpha$ rabbit polyclonal antibody (Cat. \#PA5-14709, Invitrogen Inc.) was used. PDGFR $\beta$ was probed with a (1:500) PDGFR $\beta$ rabbit polyclonal antibody (Cat. \#PA5-14718, Invitrogen Inc.).

\subsection{Stereological Methods}

Stereological methods were applied by a blinded investigator using unbiased stereology analysis (Stereologer, Systems Planning and Analysis Inc., Chester, MD, USA) to determine the total positive cell counts in 20 cortical fields on at least ten brain sections ( 400 positive cells per subject) from each animal as previously explained (Algarzae et al. 2012). c-Abl, PDGFR $\alpha$, and PDGFR $\beta$ positive stainings were assessed by optical density (OD) measurements in human post-mortem brains from the entire brain sections of all subjects.

Using an Optronics (Goleta, CA, USA) digital camera and a constant illumination table, digitalized images of c-Abl, PDGFR $\alpha$, and PDGFR $\beta$ immunostained sections were collected. Optical densities were measured using Image-Pro Plus software (Version 3.0.1; Media Cybernetics, Silver Spring, MD, USA). The OD was measured from coronal sections and the final reading was calculated as an average of those values. Non-specific background correction in each section was performed by subtracting the OD value of the corpus callosum from the cortical OD value obtained from the same section. The OD analysis was performed under blinded conditions.

\subsection{Transgenic Mouse Models of Alzheimer's Disease and Parkinson's Disease}

Experiments were conducted on C57BL/6J mice as follows: (1) young mice (aged 4-5 months) or old mice (aged 12-15 months) that express the neuronally derived human APP gene, 770 isoform, containing the Swedish K670 N/ M671L, Dutch E693Q, and Iowa D694 N mutations under the control of the mouse thymus cell antigen 1, theta, Thy1, and promoter, or (2) 6- to 8-month-old transgenic $\alpha$-syn mice harboring the arginine to threonine (A53T) mutation of human $\alpha$-syn under the control of the prion promoter [54]. All mice were purchased from Jackson Laboratory (Bar Harbor, ME, USA) and housed in the Georgetown Department of Comparative Medicine on a 12-h light/dark cycle with food and water provided ad libitum. All mouse studies were conducted in full compliance with the recommendations of the Georgetown University Animal Care and Use Committee.

\subsection{Drugs and Treatments}

Nilotinib (Cat. \#S1033), bosutinib (Cat. \#S1014), bafetinib (Cat. \#S1369), and radotinib (Cat. \#S8134) were commercially obtained from Selleckchem Inc. (Houston, TX, USA). LCB-03-0110 (Cat. \#5592) was commercially obtained from Bio-techne Corporation. (Minneapolis, MN, USA). Mice received treatments of daily IP injections of $30 \mu \mathrm{L}$ of dimethyl sulfoxide (DMSO), nilotinib $(10 \mathrm{mg} / \mathrm{kg}$ ), bosutinib $(5 \mathrm{mg} / \mathrm{kg})$, bafetinib $(2.5 \mathrm{mg} / \mathrm{kg}, 5 \mathrm{mg} / \mathrm{kg}, 10 \mathrm{mg} / \mathrm{kg})$, radotinib $(10 \mathrm{mg} / \mathrm{kg})$, or LCB $(10 \mathrm{mg} / \mathrm{kg}, 5 \mathrm{mg} / \mathrm{kg}, 2.5 \mathrm{mg} /$ $\mathrm{kg}, 1.25 \mathrm{mg} / \mathrm{kg}$ ) dissolved in DMSO. Treatment consisted of a single dose for pharmacokinetic experiments (Fig. 1), 7 consecutive days for screening experiments (Figs. 4, 5), or 21 consecutive days for all other experiments.

\subsection{Pharmacokinetic Studies}

C57BL/6J mice received an IP injection of DMSO, nilotinib, bosutinib, bafetinib, radotinib, or LCB. Brain and serum were collected at $2,4,6$, or $8 \mathrm{~h}$ ( $n=18$ per drug, $n=3$ per dose and time-point). Animals injected with the vehicle (DMSO) were used for background subtraction. Stock solutions of drug (approximately $1 \mathrm{mg} / \mathrm{mL}$ each) were prepared in methanol/dichloromethane (50:50). The serial dilutions for each of the standards were produced for the study separately in methanol/HPLC grade water (50:50). Preparation of the calibration curve standards and quality-control samples was performed by mixing the stock solutions in blank samples. Serum and brain samples were stored at $-80{ }^{\circ} \mathrm{C}$ and then thawed to RT prior to preparation. The thawed serum samples $(20 \mu \mathrm{L})$ were transfused to a tube containing $100 \mu \mathrm{L}$ of water. The $500-\mu \mathrm{L}$ extraction solvent, acetonitrile/ 


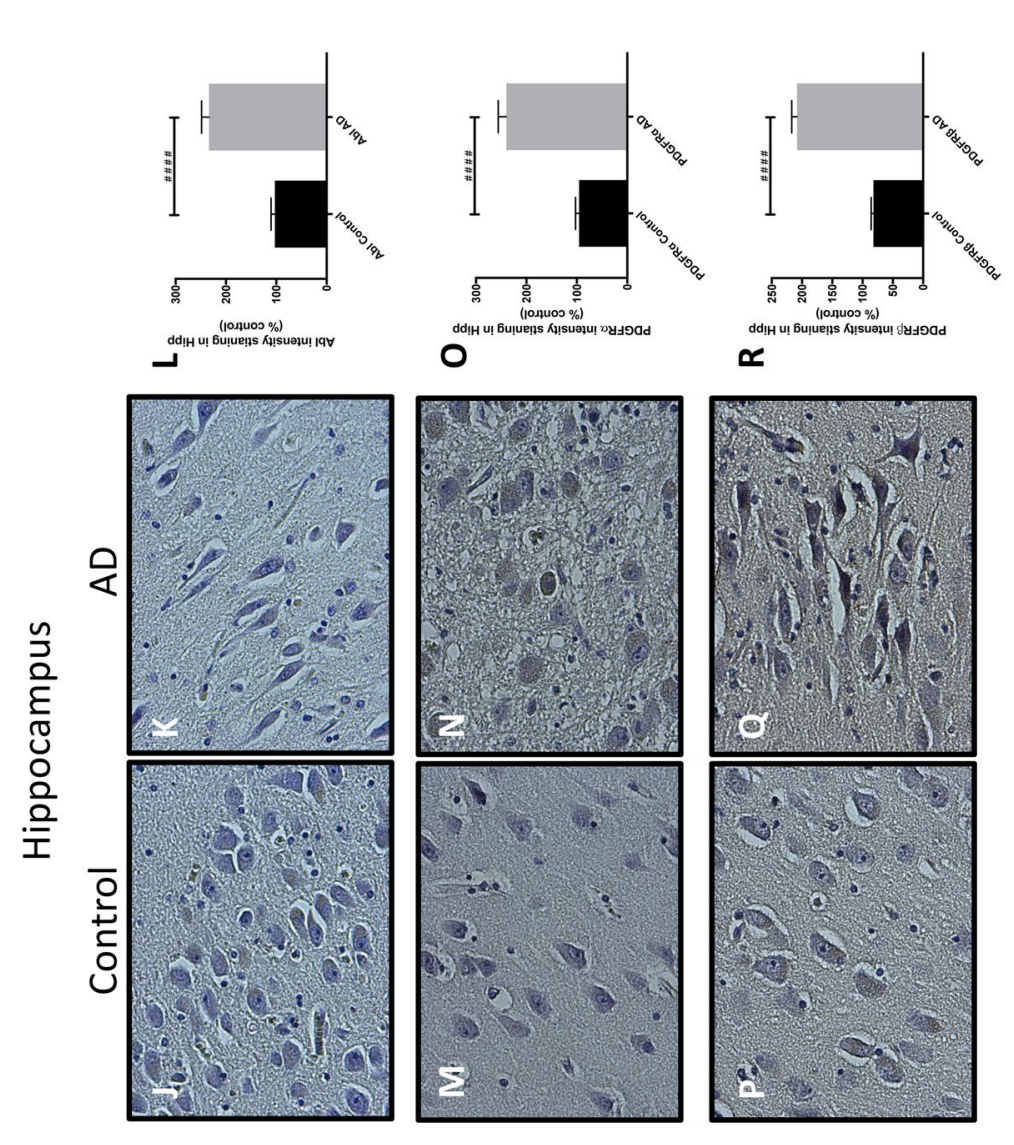

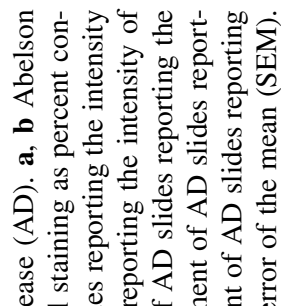

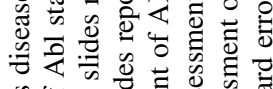

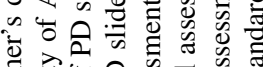

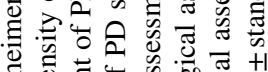

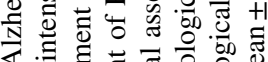

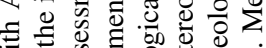

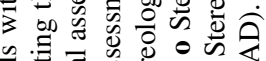

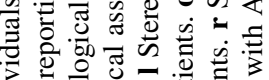

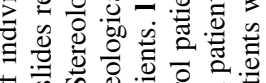

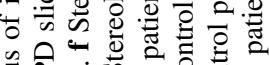

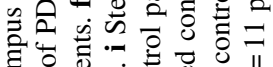

हี유

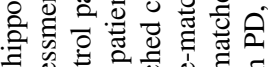

\&

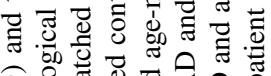

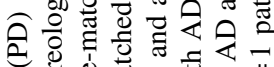

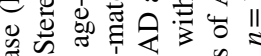

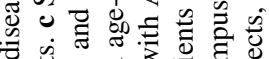

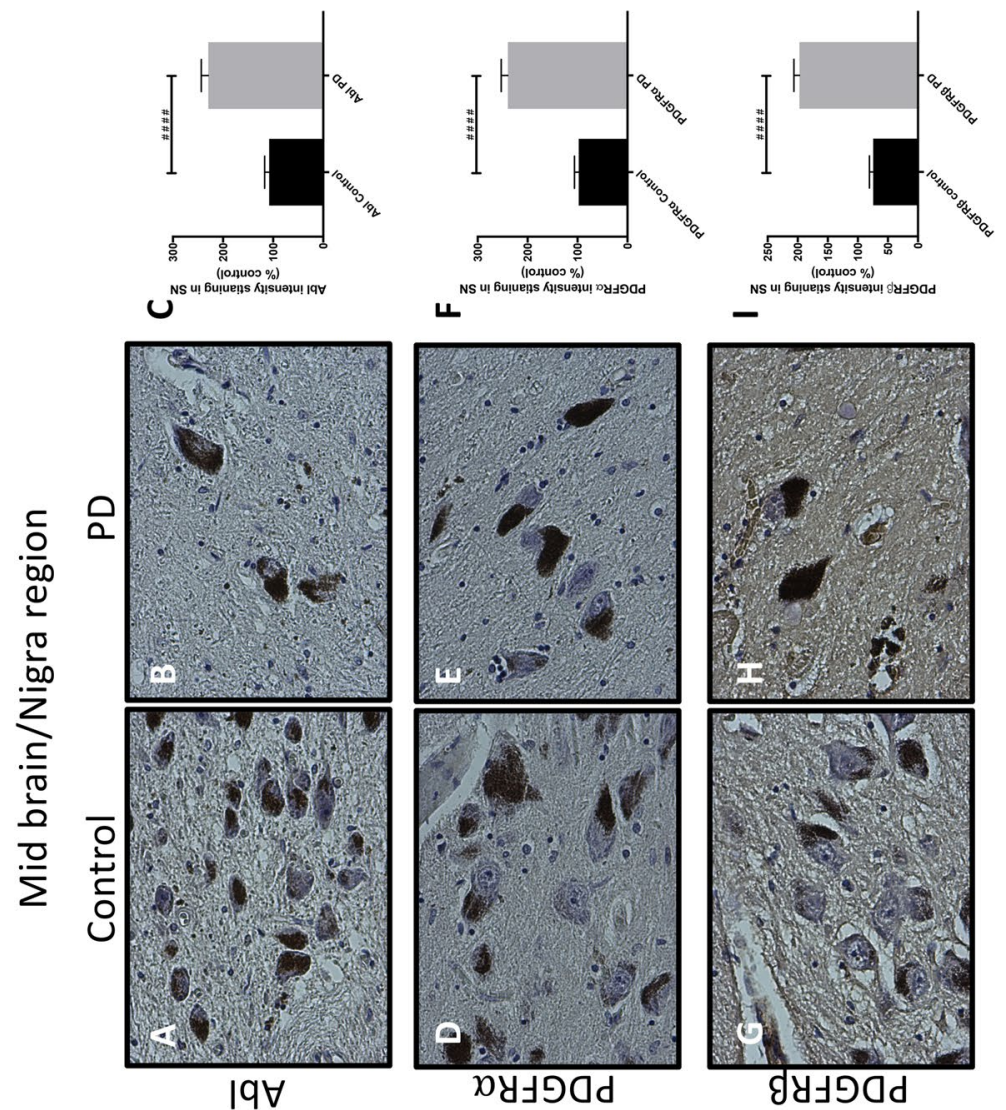

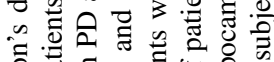

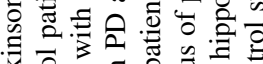

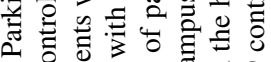

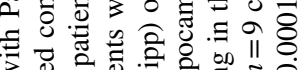

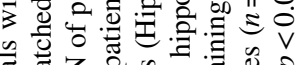

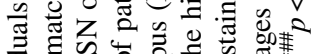

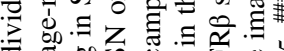

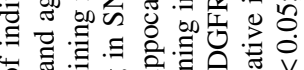

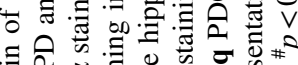

寻完的寻

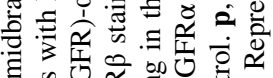

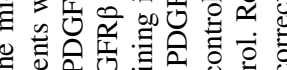

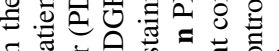

$\Xi \approx$ to

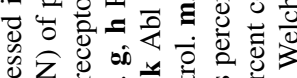

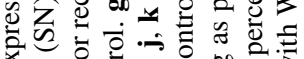

ช

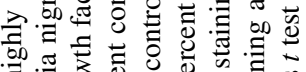

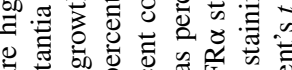

औ

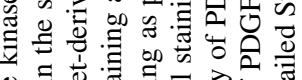

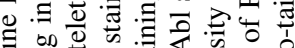

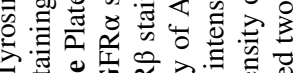

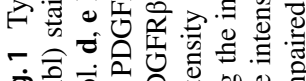

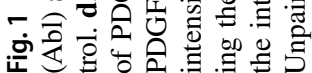


methanol (50:50) was added to the sample. The mixture was vortexed and incubated on ice for $20 \mathrm{~min}$ to accelerate protein precipitation. After incubation, the samples were vortexed again and centrifuged at 13,000 rpm for $20 \mathrm{~min}$ at $4{ }^{\circ} \mathrm{C}$. The supernatant was then collected and transferred to a new tube, dried using SpeedVac ${ }^{\mathrm{TM}}$ (Thermo Fisher Scientific, Waltham, Massachusetts, USA), and reconstituted in $200 \mu \mathrm{L}$ of methanol/water (50:50). The mixture was spun again at $13,000 \mathrm{rpm}$ for $20 \mathrm{~min}$ at $4{ }^{\circ} \mathrm{C}$. The supernatant was then collected into a mass spectrometer sample tube cap and run in the mass spectrometer.

For the brain, a small section of the thawed brain sample from each animal was transferred to a flat bottom tube. Then, $200 \mu \mathrm{L}$ of methanol/water (90:10) was added, and the tissue was homogenized. Acetonitrile was then added to the mixture facilitating protein precipitation. The mixture was incubated on ice for $10 \mathrm{~min}$. After incubation, the samples were vortexed and centrifuged at 13,000 rpm for $20 \mathrm{~min}$ at $4{ }^{\circ} \mathrm{C}$. The supernatant was then collected and transferred to a new tube, dried using SpeedVac ${ }^{\mathrm{TM}}$, and reconstituted in $200 \mu \mathrm{L}$ of methanol/water (50:50). The mixture was centrifuged at $13,000 \mathrm{rpm}$ for $20 \mathrm{~min}$ at $4{ }^{\circ} \mathrm{C}$. The supernatant was collected into a mass spectrometer sample tube cap and run in the mass spectrometer. The samples were resolved on an Acquity UPLC BEH C18 $1.7 \mathrm{~m}, 2.1 \times 50 \mathrm{~mm}$ column online with a triple quadrupole mass spectrometer (Xevo-TQ-S, Waters Corporation, Milford, Massachusetts, USA) operating in the multiple reaction monitoring mode. The sample cone voltage and collision energies were optimized for both analytes to obtain maximum ion intensity for parent and daughter ions using the "IntelliStart" feature of MassLynx software (Waters Corporation). The instrument parameters were optimized to gain maximum specificity and sensitivity of ionization for the parent $(\mathrm{m} / \mathrm{z}=438.25)$ and daughter ions $(m / z=357.33)$. Signal intensities from all multiple reaction monitoring Q1/Q3 ion pairs for analytes were ranked to ensure selection of the most intense precursor and fragment ion pair for multiple reaction monitoring-based quantitation. This approach resulted in the selection of cone voltages and collision energies that maximized the generation of each fragment ion species. An analysis was performed with a six- to eight-point calibration curve, the sample queue was randomized, and solvent blanks were injected to assess sample carryover. Multiple reaction monitoring data were processed using TargetLynx 4.1. The relative quantification values of analytes were determined by calculating the ratio of peak areas of transitions of samples normalized to the peak area of the internal standard.

\subsection{Tissue Collection and Protein Extraction}

Animals were deeply anesthetized with a mixture of xylazine and ketamine (1:8), and $500 \mu \mathrm{L}$ of whole blood was collected via cardiac puncture, centrifuged at $2000 \times g$ to precipitate blood cells, and the serum was collected. To wash out the remaining blood from vessels and reduce contamination, animals were perfused with $25 \mathrm{~mL}$ of $1 \times$ phosphate buffered saline for $5 \mathrm{~min}$. Brains were collected and homogenized in $1.0 \mathrm{~mL}$ of sodium Tris EDTA NP-40 (STEN) lysis buffer (containing protease and phosphatase inhibitors). Homogenized samples were centrifuged at $12,000 \times g$ for $20 \mathrm{~min}$ at $4{ }^{\circ} \mathrm{C}$ and the supernatant was collected and stored at $-80^{\circ} \mathrm{C}$.

\subsubsection{Insoluble Protein Extraction}

After removing the "soluble" supernatant, the tissue pellet was washed with $1 \times$ sodium Tris EDTA NP-40 buffer. The pellet was re-suspended in $750 \mu \mathrm{L}$ of $70 \%$ formic acid and incubated for $30 \mathrm{~min}$ at RT followed by a centrifugation at $28,000 \times g$ at $4{ }^{\circ} \mathrm{C}$ for $1 \mathrm{~h}$. The supernatant was collected as the "insoluble fraction". Samples from the $70 \%$ formic acid fraction were stored at $-80{ }^{\circ} \mathrm{C}$ and neutralized with $1 \mathrm{M}$ Tris-base (1:20) immediately before use.

\subsection{Western Blot Analysis and Antibodies}

Soluble fractions were probed with (1:1000) mouse monoclonal anti-6E10 (Covance SIG-39320), (1:1000) rabbit polyclonal anti-A $\beta_{42}$ (Covance SIG-39153), (1:1000) rabbit monoclonal anti-AT180 (Cat. \#151559, Abcam, Cambridge, Cambridgeshire, England), (1:1000) rabbit polyclonal antiBeclin-1 (Cat. \#D40C5, Cell Signaling Technology, Danvers, Massachusetts, USA), (1:1000) rabbit polyclonal antiAtg7 (Cat. \#D12B11, Cell Signaling Technology), (1:1000) rabbit polyclonal anti-Atg12 (Cat. \#D88H11, Cell Signaling Technology), (1:1000) rabbit polyclonal anti-LC3B (Cat. \#PA1-16931, Invitrogen Inc.), $\alpha$-syn (Cat. \#Ma112874, ThermoFisher, Waltham, Massachusetts, USA), and (1:1000) rabbit polyclonal anti-actin (Cat. \#MAB1501R, Millipore, Burlington, Massachusetts, USA).

\subsection{Enzyme-Linked Immunosorbent Assay}

Human $A \beta_{42}$ enzyme-linked immunosorbent assay (ELISA) [Cat. \#KHB3544, Invitrogen Inc.] was performed using $50 \mu \mathrm{L}(1 \mu \mathrm{g} / \mu \mathrm{L})$ of insoluble proteins suspended in $30 \%$ formic acid and detected with $\mathrm{A} \beta$ primary antibodies $(3 \mathrm{~h})$ and $100 \mu \mathrm{L}$ of anti-rabbit antibodies (30 min) at RT. Extracts were incubated with stabilized chromogen for $30 \mathrm{~min}$ at RT and solution was stopped and read at $450 \mathrm{~nm}$, according to the manufacturer's protocol.

Human $\alpha$-syn and p-tau ELISA were performed using $50 \mu \mathrm{L}(1 \mu \mathrm{g} / \mu \mathrm{L})$ of soluble fraction detected with $50 \mu \mathrm{L}$ of primary antibodies $(3 \mathrm{~h})$ and $100 \mu \mathrm{L}$ of anti-rabbit secondary antibodies (30 mins) at RT. Alph $\alpha$-synuclein levels were measured using human-specific ELISA (Cat. \#844101, 
BioLegend, San Diego, CA, USA) according to the manufacturer's protocols. P-tau was measured using specific p-tau at serine 396 (S396) [Cat. \#KHB7031, Invitrogen Inc.] or p-tau at threonine 231 (pT231) [Cat. \#KHB8051, Invitrogen Inc.] according to the manufacturer's protocol. Each sample was duplicated.

\subsection{Immunohistochemistry}

Animals were deeply anesthetized with a mixture of xylazine and ketamine (1:8), washed with normal saline for $1 \mathrm{~min}$, and then perfused with 4\% paraformaldehyde for 15-20 min. Brains were quickly dissected out and immediately stored in $4 \%$ paraformaldehyde for $24 \mathrm{~h}$ at $4{ }^{\circ} \mathrm{C}$, and then transferred to $30 \%$ sucrose at $4{ }^{\circ} \mathrm{C}$ for $48 \mathrm{~h}$. Brains were cut using a cryostat microtome into $20-\mu \mathrm{M}$-thick coronal sections and stored at $-20{ }^{\circ} \mathrm{C}$. Primary anti- $\beta$-amyloid, $1-16$ (1:300, 803001; BioLegend) mouse antibody was applied overnight at $4{ }^{\circ} \mathrm{C}$. An anti-mouse 3,3'-diaminobenzidine secondary antibody (1:300, PK-2200; Vector, Burlingame, CA, USA) was applied as per the manufacturer's protocol. Quantification of plaque load was performed using Image J with a nonspecific background correction and mean staining intensity of 6E10 3,3'-diaminobenzidine was quantified and averaged between images within treatment group hippocampus and cortex regions and then compared between treatment groups. Cupric silver staining was performed with the FD NeuroSilver Kit II as per the manufacturer's protocol (PK301 A; FD NeuroTechnologies, Inc., Columbia, MD, USA).

\subsection{Milliplex Enzyme-Linked Immunosorbent Assay}

Xmap technology uses magnetic microspheres that are internally coded with two fluorescent dyes. Through precise combinations of these two dyes, multiple proteins are simultaneously measured within a sample. Each of these spheres is coated with a specific capture antibody. The capture antibody binds to the detection antibody and a reporter molecule, completing the reaction on the surface of the bead. All samples including placebo and resveratrol at baseline and 52 weeks were analyzed in parallel using the same reagents. A total of $25 \mu \mathrm{L}$ of soluble protein was incubated overnight at $4{ }^{\circ} \mathrm{C}$ with $25 \mu \mathrm{L}$ of a mixed-bead solution containing total tau, $\mathrm{AB}_{40}$, and $\mathrm{AB}_{42}$ (Cat. \#HNABTMAG $60 \mathrm{~K}$, Millipore). After washing, samples were incubated with $25 \mu \mathrm{L}$ of detection antibody solution for $1.5 \mathrm{~h}$ at RT. Streptavidin-phycoerythrin $(25 \mu \mathrm{L})$ was added to each well containing $25 \mu \mathrm{L}$ of detection antibody solution. Samples were then washed and suspended in $100 \mu \mathrm{L}$ of sheath fluid. Next, samples were run on MAGPIX with Xponent software.
The median fluorescent intensity data were analyzed using a five-parameter logistic or spline curve-fitting method for calculating analyte concentrations in samples.

\subsection{Statistical Methods}

All graphs and statistical analyses were performed in GraphPad Prism Software Version 7.0 (Graphpad Prism Software Inc., La Jolla, CA, USA). The number ( $n$ ) indicates the number of individual animals used in each group. Asterisks designate significant differences for analysis of variance and pound symbols designate significant differences for $t$ tests. Significance was assumed at $p<0.05$ and determined by analysis of variance, with Tukey's multiple comparison test, or the unpaired two-tailed Student's $t$ test when appropriate with Welch's correction.

\section{Results}

\subsection{Tyrosine Kinases are Highly Expressed in the Midbrain of Individuals with Parkinson's Disease and the Hippocampus of Individuals with Alzheimer's Disease}

We have previously reported that DDR $1 / 2$ expression is increased in the midbrains and hippocampus of post-mortem tissues from individuals with $\mathrm{PD}$ and $\mathrm{AD}$, respectively [2]. Specifically, stereological quantification shows that DDR1 and DDR2 expressions were increased in AD by $41 \%$ and $67 \%$, respectively. In PD, quantification of DDR1 and DDR2 expression was increased by $23 \%$ and $71 \%$, respectively [2]. Because Abl and DDRs are already reported to be upregulated in human NDs and animal models of $\mathrm{AD}$ and PD, we explored the expression profiles of several other TKs and compared them to Abl. To determine the expression profiles of TKs associated with neurodegeneration, post-mortem PD midbrains ( $n=10)$, post-mortem AD hippocampus $(n=11)$, and age-matched controls $(n=9)$ were sectioned and stained for Abl, PDGFR $\alpha$, and PDGFR $\beta$ (Fig. 1). Stereological assessment of the staining intensity indicates that Abl (Fig. 1c), PDGFR $\alpha$ (Fig. 1f), and PDGFR $\beta$ (Fig. 1i) are significantly upregulated in the substantia nigra of the post-mortem PD tissue samples. The data also indicate that Abl (Fig. 11), PDGFR $\alpha$ (Fig. 1o), and PDGFR $\beta$ (Fig. 1r) are significantly upregulated in the hippocampus of the postmortem AD tissue samples.

After identifying that Abl, PDGFR $\alpha$, and PDGFR $\beta$ were upregulated, we created shRNA clones to knockdown each of these TKs in cell culture and animal models [Figs. 1 and 2 of the Electronic Supplementary Material (ESM)]. We identified two shRNA clones, one that potently knocked down Abl (Abl shRNA) and a control 
shRNA that did not have any effect on Abl (Abl mock) in rat B35 neuroblastoma (data not shown). Abelson shRNA was injected into the right (ipsilateral) hippocampus and Abl mock shRNA was injected into the left (contralateral) hippocampus of 4 - to 5-month old APP mice $(n=4)$. Western blot analysis for $\mathrm{Abl}$ in these mice shows that $\mathrm{Abl}$ is significantly reduced in the ipsilateral hemisphere, which received the Abl shRNA, compared with the contralateral hemisphere (Fig. 1A and B of the ESM; $p<0.01$ ). The ELISA of the insoluble and soluble $A \beta_{42}$ levels indicate that the ipsilateral hemisphere had significantly reduced levels of $\mathrm{A} \beta_{42}$ compared with the contralateral hemisphere (Fig. 1C and D of the ESM; $p<0.01$ ). We also identified shRNA clones that knock down PDGFR $\alpha$ (Fig. 2A of the ESM) and PDGFR $\beta$ (Fig. 2D of the ESM). These clones were tested in rat B35 neuroblastoma that were transfected with $A \beta_{42}$ to find the clone that potently knocks down the gene (Fig. 2B and E of the ESM). We then tested the shRNA clones in the transfected cells with and without co-treatment of $10 \mu \mathrm{M}$ of nilotinib (Fig. 2C and F of the ESM). The shRNA for PDGFR $\alpha$ and PDGFR $\beta$ showed similar results to the ability of nilotinib to reduce $A \beta_{42}$, and when the transfected cells were treated with both shRNA and nilotinib there was a more robust response to reduce $\mathrm{A} \beta_{42}$ (Fig. $2 \mathrm{C}$ and $\mathrm{F}$ of the ESM). Together, our data indicate that several TKs are upregulated in human $\mathrm{PD}$ and $\mathrm{AD}$ brains and knockdown of these TKs in cells or transgenic mouse models results in decreased neurotoxic protein burden.

\subsubsection{Pharmacokinetics and Pharmacodynamics of Nilotinib, Bafetinib, Bosutinib, Radotinib, and LCB}

Several TKIs were evaluated to determine their pharmacokinetics and compare their pharmacodynamic effects at comparable doses that were previously found to be effective at reducing neurotoxic protein levels. To determine the brain penetrance of each TKI, wild-type male C57BL/6 J ( $n=18$ per drug) mice received a single IP injection of $10 \mathrm{mg} / \mathrm{kg}$ of nilotinib (Fig. 2a), $5 \mathrm{mg} / \mathrm{kg}$ of bafetinib (Fig. 2b), $5 \mathrm{mg} / \mathrm{kg}$ of bosutinib (Fig. 2c), $10 \mathrm{mg} /$ $\mathrm{kg}$ of radotinib (Fig. 2d), $2.5 \mathrm{mg} / \mathrm{kg}$ of LCB (Fig. 2e), or $1.25 \mathrm{mg} / \mathrm{kg}$ of LCB (Fig. 2f) all dissolved in DMSO. Injected mice ( $n=3$ per time-point) were sacrificed at 1 , $2,4,8$, and $12 \mathrm{~h}$ after injection and data were normalized to DMSO-treated mice. The brain and plasma concentrations of the drug were assessed using mass spectrometry. No drug was detected in the brain after the 4-h time-point, while their plasma concentrations declined progressively until they were undetected at the 8-h time-point. The data (Fig. 2a-f) summarized in Table 1 show that the maximum concentration of every drug peaked at the 1-h time-point. The highest concentration at $1 \mathrm{~h}$ was bafetinib at $2362 \mathrm{nM}$,
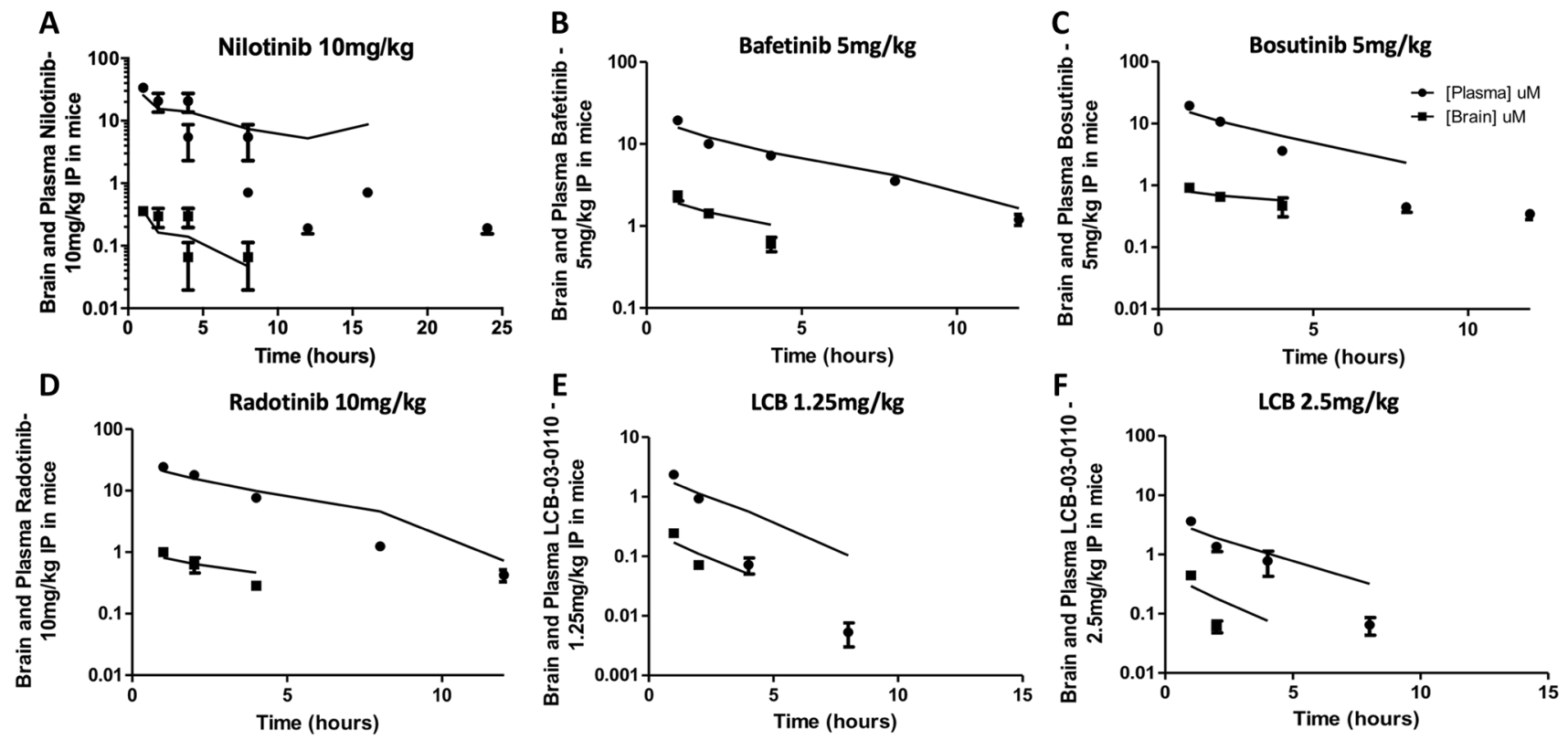

Fig. 2 Pharmacokinetics and pharmacodynamics of nilotinib, bafetinib, bosutinib, radotinib, and LCB. C57BL/6 J mice were given a single intraperitoneal (IP) injection of a $10 \mathrm{mg} / \mathrm{kg}$ of nilotinib, $\mathbf{b}$ $5 \mathrm{mg} / \mathrm{kg}$ of bafetinib, $\mathbf{c} 5 \mathrm{mg} / \mathrm{kg}$ of bosutinib, $\mathbf{d ~} 10 \mathrm{mg} / \mathrm{kg}$ of radotinib, e $1.25 \mathrm{mg} / \mathrm{kg}$ of LCB, or $\mathbf{f} 2.5 \mathrm{mg} / \mathrm{kg}$ of LCB ( $n=3$ per time-point, $n=18$ per drug). Brain and plasma were collected and drug concentration was assessed at $1,2,3,4,8$, and $12 \mathrm{~h}$ using mass spectrometry and plotted as concentration $(\mu \mathrm{M})$ vs. time (hours). All values are reported in Table 1 


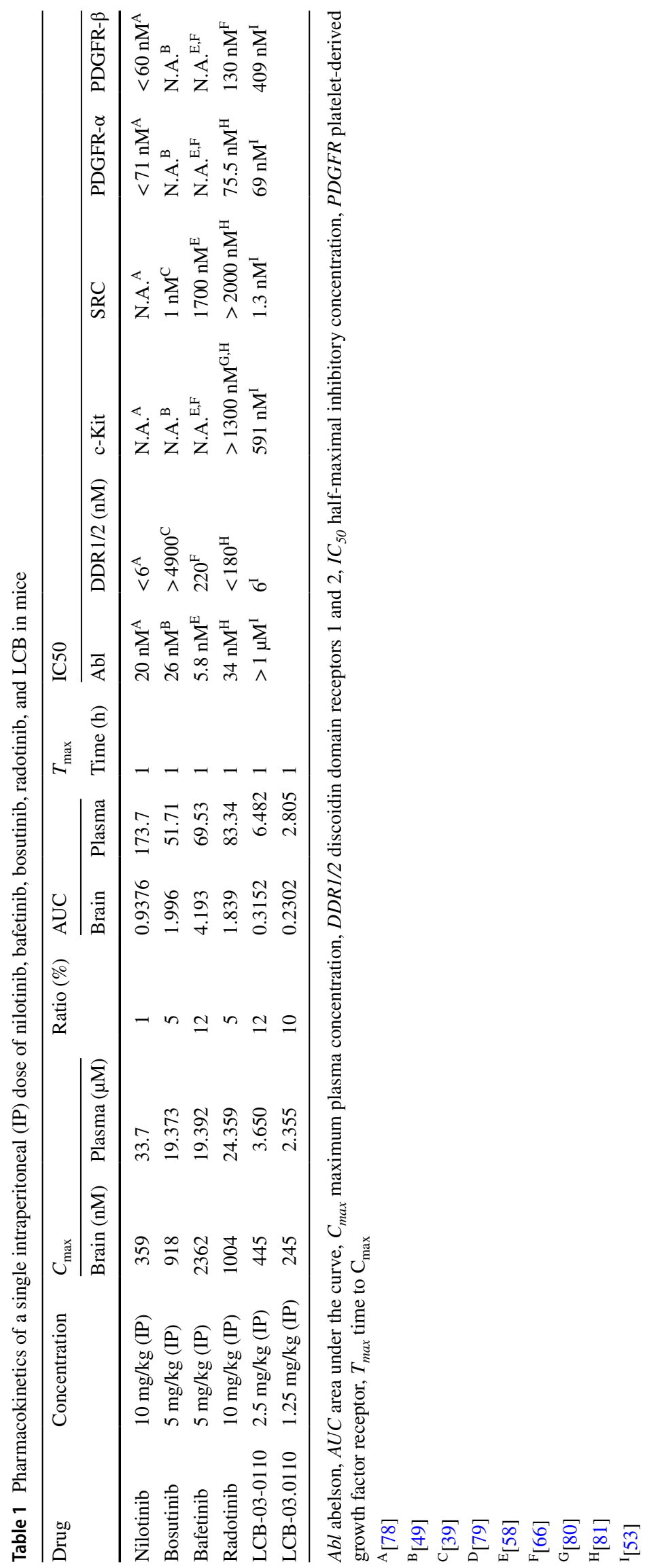


while the lowest concentration at $1 \mathrm{~h}$ was $1.25 \mathrm{mg} / \mathrm{kg} \mathrm{LCB}$ at $245 \mathrm{nM}$ (Table 1).

\subsubsection{Multi-Target Abelson Inhibitors, Nilotinib and Radotinib Differentially Affect Amyloid- $\beta$ and tau Pathology in APP Mice}

To evaluate the efficacy of radotinib to reduce neurotoxic protein load in a model of $\alpha$-synucleinopathy, 12-month-old A53T mice $(n=3)$ were given an IP injection with $5 \mathrm{mg} / \mathrm{kg}$ of radotinib or DMSO once daily for 3 consecutive weeks. We previously demonstrated that $1-10 \mathrm{mg} / \mathrm{kg}$ of nilotinib can effectively reduce $\alpha$-syn levels in A53T mice that carry the human mutant A53T $\alpha$-syn transgene and overexpress $\alpha$-syn predominantly in the striatum [37]. To compare the effects of radotinib to nilotinib, A53T mice were treated with $5 \mathrm{mg} / \mathrm{kg}$ of IP radotinib once a day for 3 consecutive weeks. Western blot analysis shows there is no change in $\alpha$-syn levels compared to DMSO-treated animals (Fig. 3a). The ELISAs also show there is no difference in $\alpha$-syn levels between $5 \mathrm{mg} / \mathrm{kg}$ of radotinib and DMSO treatment (Fig. 3b). We also compared the efficacies of nilotinib and radotinib in 4- to 7-month-old APP mice, which express neuronally derived human APP harboring the Swedish K670 N/ M671L, Dutch E693Q, and Iowa D694 N mutations under the control of the mouse thymus cell antigen 1 promoter. All mice were injected intraperitoneally with either $10 \mathrm{mg} / \mathrm{kg}$ of nilotinib or $10 \mathrm{mg} / \mathrm{kg}$ of radotinib for 3 consecutive weeks.
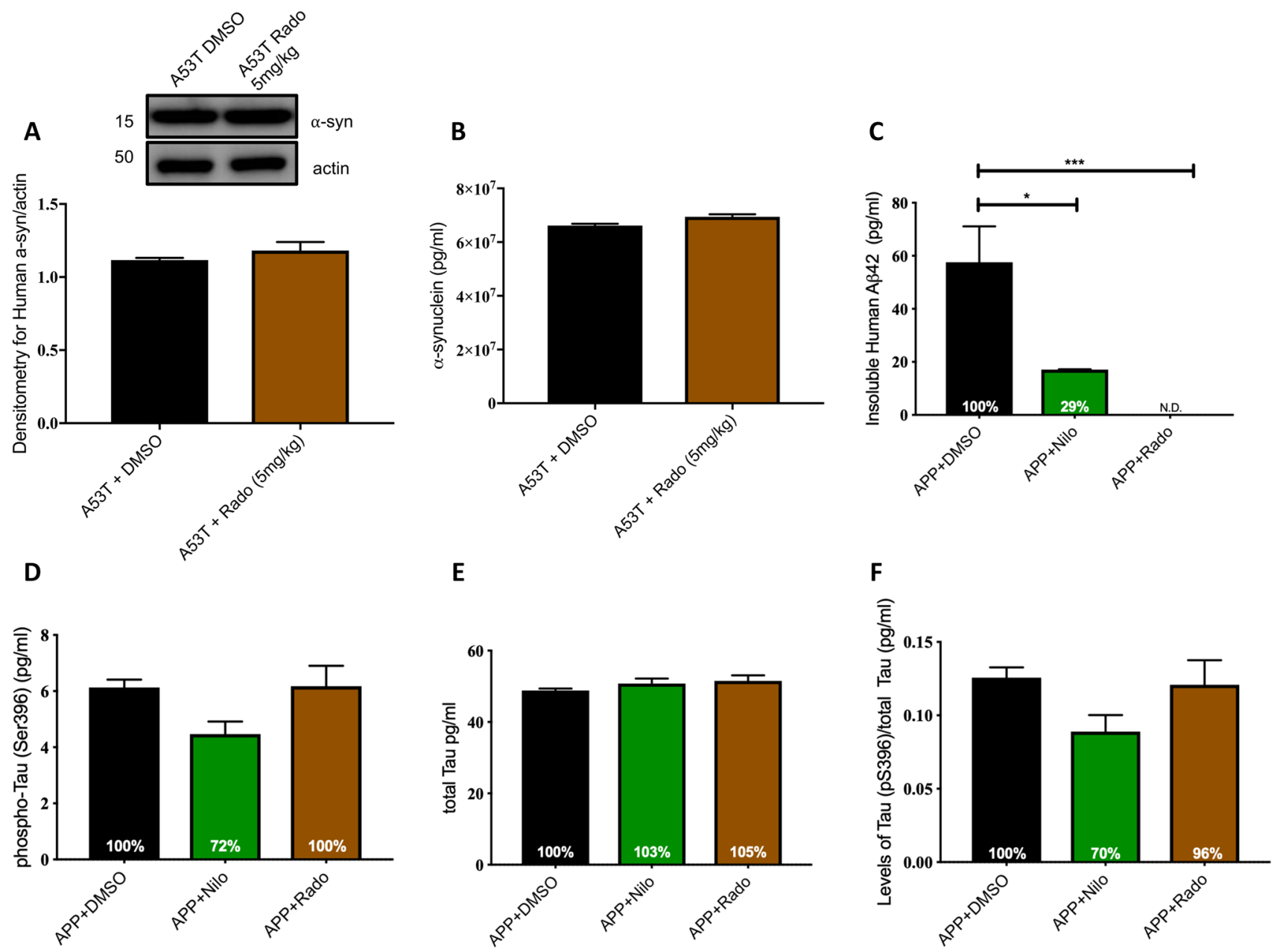

Fig. 3 Multi-target abelson (Abl) inhibitor radotinib has no effect on $\alpha$-synuclein in the A53T mouse at low doses and at high doses differentially affects amyloid- $\beta(\mathrm{A} \beta)$ and tau pathology in APP mice compared to nilotinib. The 12-month-old A53T mice $(n=3)$ were given a daily intraperitoneal (IP) injection with dimethyl sulfoxide [DMSO] $(n=3)$ or $5 \mathrm{mg} / \mathrm{kg}$ of radotinib $(n=3)$ for 21 consecutive days. a Western blot representative images and densitometry probed with human $\alpha$-synuclein (ThermoFisher, Cat. \#Ma1-12874) and actin (EMD-Millipore, Cat. \#MAB1501R), b human $\alpha$-synuclein enzyme- linked immunosorbent assay (ELISA). The 4- to 7-month-old APP mice were given a daily IP injection with DMSO $(n=3), 10 \mathrm{mg} / \mathrm{kg}$ of nilotinib $(n=7-10)$, or $10 \mathrm{mg} / \mathrm{kg}$ of radotinib $(n=7-10)$ for $21 \mathrm{con}-$ secutive days. ELISA concentrations $(\mathrm{pg} / \mathrm{mL})$ of $\mathbf{c}$ insoluble human A 342 , d phospho-tau (Ser396), e total tau, and $\mathbf{f}$ ratio of phopsho-tau (Ser396) to total tau. Levels of protein that are not detected in the assay are indicated as (N.D.) mean \pm standard deviation (SD). Ordinary one-way analysis of variance (ANOVA), Tukey's multiple comparison test, ${ }^{*} p<0.05 ; * * * p<0.001$ 
These mice develop age-related $\mathrm{A} \beta$ and tau expression and protein accumulation $[3,35]$. Insoluble human $A \beta$ was significantly decreased by both nilotinib and radotinib (Fig. 3c; $p<0.01,0.001$ ). Additionally, nilotinib reduced the amount of phospho-tau by $28 \%$ compared with DMSO (ser396) with no effect on the level of total tau, while radotinib had no effect on the phosphorylated or total tau levels (Fig. 3d, e). There is a slight reduction (30\%) in the ratio of phospho-tau (Ser396) to total tau levels in nilotinib-treated animals and not in radotinib-treated animals (Fig. 3f).

\subsubsection{Bafetinib, an Abelson Inhibitor, Does Not Ameliorate a-Synuclein Pathology in A53T Mice}

To determine the efficacy of bafetintib in a model of $\alpha$-synucleinopathy, 8- to 10 -month old transgenic A53T mice were injected intraperitoneally with $10 \mathrm{mg} / \mathrm{kg}, 5 \mathrm{mg} /$ $\mathrm{kg}$, or $2.5 \mathrm{mg} / \mathrm{kg}$ of bafetinib or DMSO ( $n=6$ per group) once daily for 3 consecutive weeks $(n=6$ per treatment group). The protein ELISA for human $\alpha$-syn shows that A53T DMSO-treated animals have significantly higher levels of $\alpha$-syn compared with wild-type mice (Fig. 4a). We have shown earlier (Fig. 2b) that bafetinib is able to penetrate the brain within $5 \mathrm{~h}$, similarly to nilotinib. However, the $10-\mathrm{mg} / \mathrm{kg}, 5-\mathrm{mg} / \mathrm{kg}$, or $2.5-\mathrm{mg} / \mathrm{kg}$ dose of bafetinib did not reduce the levels of $\alpha$-syn measured via ELISA (Fig. 4a).
A

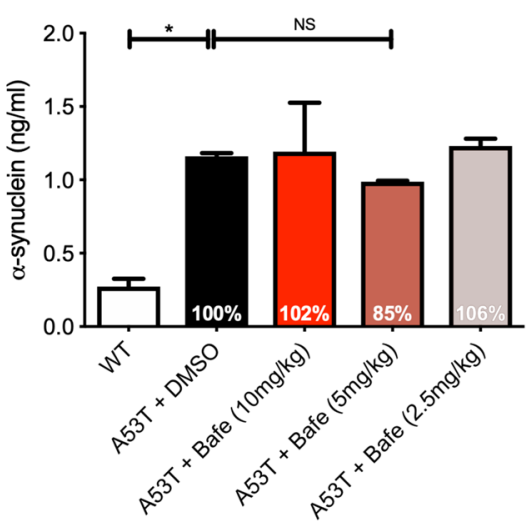

D

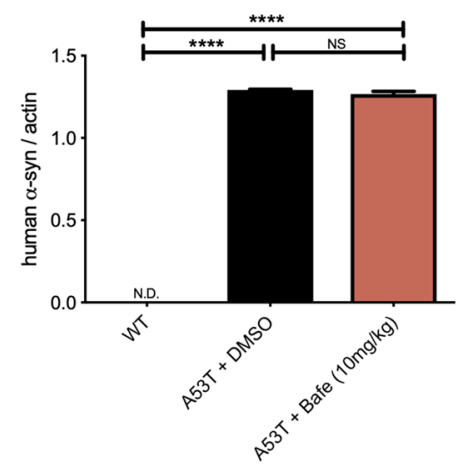

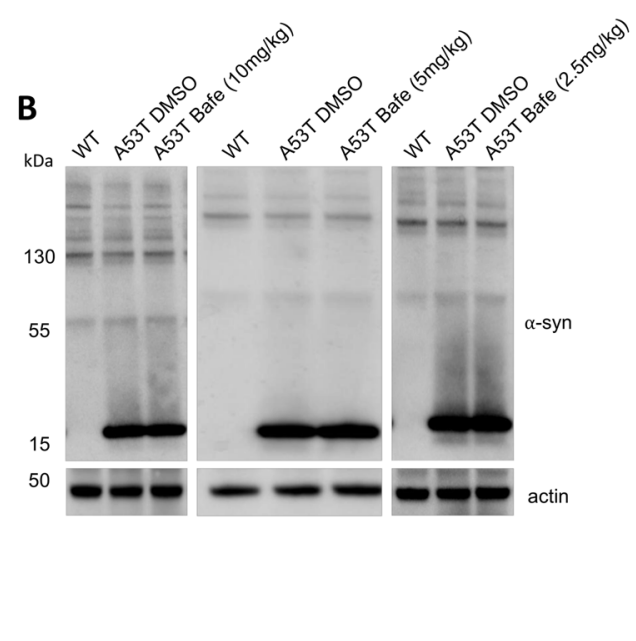

E

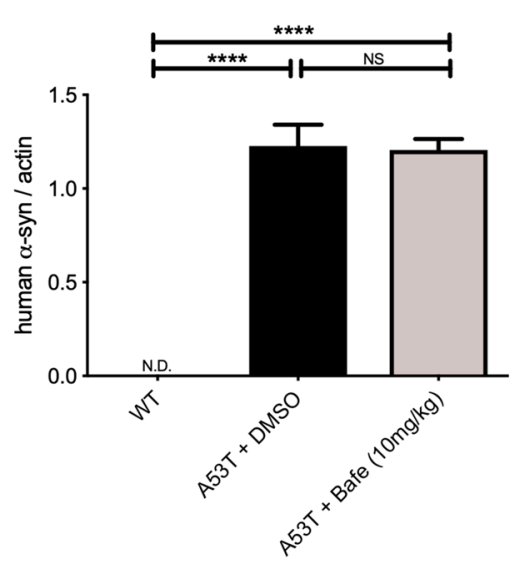

C
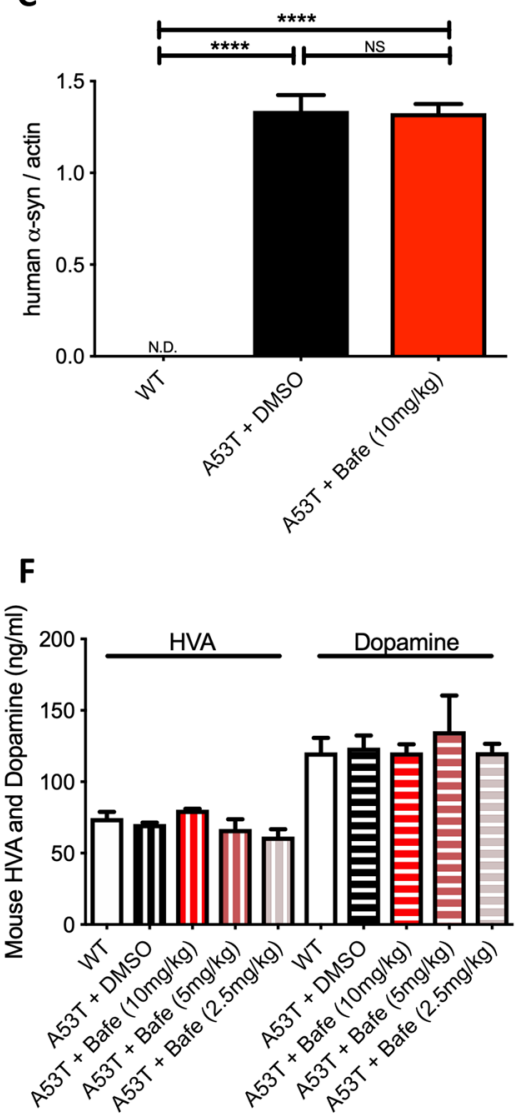

Fig. 4 Bafetinib, an abelson (Abl) inhibitor, does not ameliorate $\alpha$-synuclein in A53T mice. Eight- to ten-month-old A53T mice were given a daily intraperitoneal (IP) injection daily with $10 \mathrm{mg} /$ $\mathrm{kg}, 5 \mathrm{mg} / \mathrm{kg}$, and $2.5 \mathrm{mg} / \mathrm{kg}$ of bafetinib for 7 consecutive days $(n=6$ per treatment group). a Alpha-synuclein enzyme-linked immunosorbent assay (ELISA) concentration. b Western blot image probed with $\alpha$-synuclein (ThermoFisher, Cat. \#Ma1-12874) and actin (EMDMillipore, Cat. \#MAB1501R). c Alphs-synuclein densitometry with
$10 \mathrm{mg} / \mathrm{kg}$ of bafetinib. d Alpha-synuclein densitometry with $5 \mathrm{mg} /$ $\mathrm{kg}$ of bafetinib. e Alpha-synuclein densitometry with $2.5 \mathrm{mg} / \mathrm{kg}$ of bafetinib. f ELISA concentrations of homovanillic acid (HVA) and dopamine. Levels of protein that are not detected in the assay are indicated as (N.D.). Mean \pm standard error of the mean (SEM). Ordinary one-way analysis of variance, Tukey's multiple comparison test, ${ }^{*} p<0.05, * * * * p<0.0001$ 
Western blot densitometry analysis also shows that A53T mice treated with DMSO have significantly higher levels of $\alpha$-syn compared with wild-type mice and that $10 \mathrm{mg} / \mathrm{kg}$ (Fig. 4b, c), 5 mg/kg (Fig. 4b, d), or 2.5 mg/kg (Fig. 4b, e) of bafetinib reduced $\alpha$-syn levels in these mice (Fig. $4 b-e$ ). Additionally, ELISA homovanillic acid and dopamine measurements remain unchanged with bafetinib treatment, indicating that bafetinib has no effect on midbrain dopamine metabolism (Fig. 4f).
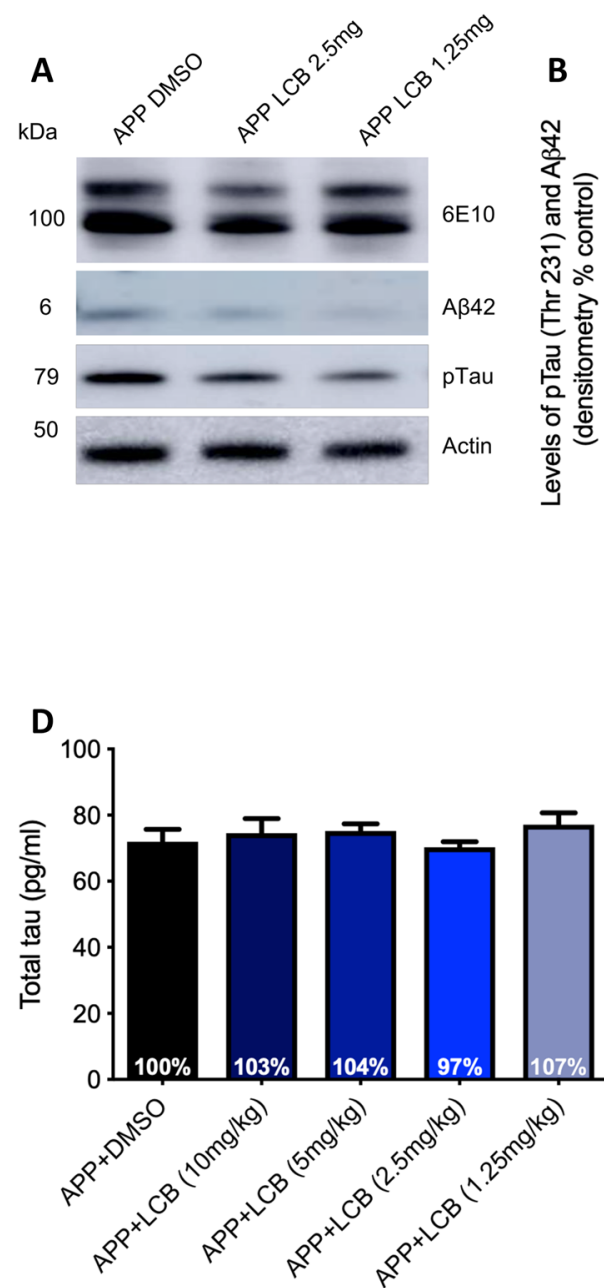
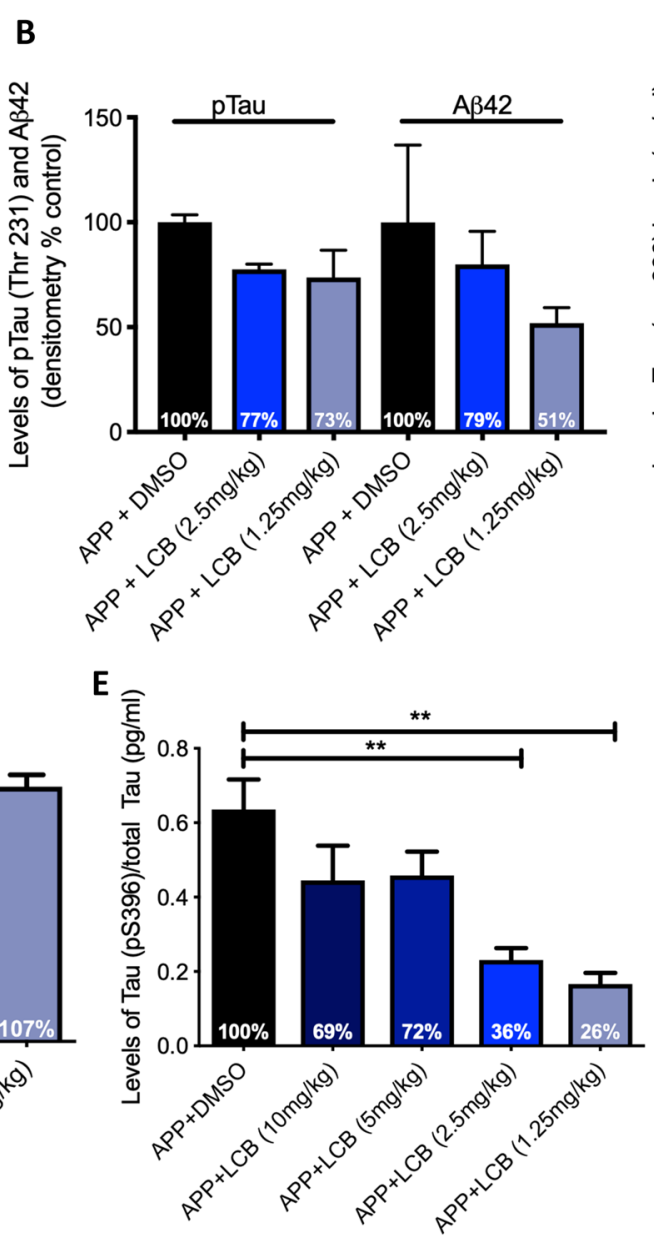

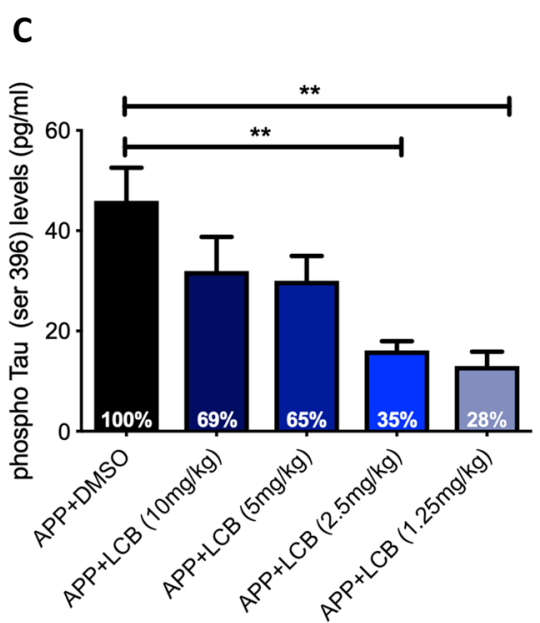

Fig. $5 \mathrm{LCB}$, a potent discoidin domain receptors 1 and 2 (DDR1/2) inhibitor, ameliorates amyloid- $\beta(\mathrm{A} \beta)$ and tau pathology in APP mice. Twelve- to fifteen-month-old APP mice were given a daily intraperitoneal (IP) injection with $10 \mathrm{mg} / \mathrm{kg}, 5 \mathrm{mg} / \mathrm{kg}, 2.5 \mathrm{mg} / \mathrm{kg}$, or $1.25 \mathrm{mg} / \mathrm{kg}$ of LCB for 7 consecutive days $(n=5$ per treatment group). Enzyme-linked immunosorbent assay (ELISA) concentrations from brain lysates of a Western blot probed with Tau 6E10, A $\beta 42$,

\subsubsection{LCB, a Potent Discoidin Domain Receptor $1 / 2$ Inhibitor, Ameliorates Amyloid- $\beta$ and tau Pathology in APP Mice}

To determine the efficacy of LCB in a transgenic animal model of AD, $10-\mathrm{mg} / \mathrm{kg}, 5-\mathrm{mg} / \mathrm{kg}, 2.5-\mathrm{mg} / \mathrm{kg}$, and $1.25-$ $\mathrm{mg} / \mathrm{kg}$ doses of LCB were evaluated in 4-month-old transgenic APP mice, which were injected intraperitoneally with DMSO or LCB daily for 7 consecutive days $(n=5$ per treatment group). Western blot immunostaining indicates that full-length APP (6E10) does not change with LCB treatments (Fig. 5a); however, A $\beta 42$ and phosphotau (AT180) decrease in an inverse dose-dependent manner (Fig. 5a, b). The densitometry of the immunostaining indicates that lower doses of LCB reduce phospho-tau 
(AT 180 ) by up to $27 \%$ and $A \beta 42$ by up to $49 \%$ compared to DMSO treatment, although these data do not reach significance with appropriate statistical tests (Fig. 5b). The ELISA shows a significant reduction in phospho-tau (Ser396) levels in APP mice treated only with $2.5 \mathrm{mg} / \mathrm{kg}$ and $1.25 \mathrm{mg} / \mathrm{kg}$ (Fig. 5c; $p<0.01$ ) with no change in total tau levels between treatment groups (Fig. 5d). Additionally, there is a significant reduction in the ratio of phospho-tau (Ser396) to total tau in the low-dose, $2.5-\mathrm{mg} / \mathrm{kg}$, and $1.25-\mathrm{mg} / \mathrm{kg}$ LCB treatment groups (Fig. $5 \mathrm{e} ; p<0.01$ ).

\subsubsection{Low Dose of $2.5 \mathrm{mg} / \mathrm{kg}$ of LCB-03-011 and Not $5 \mathrm{mg} /$ kg of Bafetinib Ameliorates Amyloid- $\beta$ and tau and Reduces Amyloid- $\beta$ Plaque Burden in APP Mice}

To compare the efficacies of the identified optimal doses of LCB and bafetinib in APP mice, 4- to 7-month-old APP or age-matched C57BL/6 J control mice were injected intraperitoneally with $2.5 \mathrm{mg} / \mathrm{kg}$ of LCB $(n=8), 5 \mathrm{mg} / \mathrm{kg}$ of bafetinib $(n=8)$, or DMSO $(n=5)$ for 3 consecutive weeks.
The ELISA indicates that soluble human $\mathrm{A} \beta_{40}$ and $\mathrm{A} \beta_{42}$ are significantly increased in APP mice compared with control mice (Fig. 6a, b). Bafetinib $5 \mathrm{mg} / \mathrm{kg}$ reduces the level of soluble $A \beta_{40}$ by only $9 \%$ (Fig. 6a) compared to DMSO. LCB had a more robust effect compared with bafetinib, significantly reducing the level of soluble $\mathrm{A} \beta_{40}$ compared with DMSO-treated mice and bafetinib-treated mice (Fig. 6a). Analysis of soluble $A \beta_{42}$ indicates that here bafetinib did significantly reduce the level of $A \beta_{42}$ compared with DMSOtreated mice. However, again, the level of soluble $A \beta_{42}$ was significantly reduced with LCB compared with DMSO and bafetinib-treated mice (Fig. 6b). When the insoluble $A \beta_{42}$ was assessed there was no significant changes detected, but there was a slight reduction in the insoluble $\mathrm{A} \beta_{42}$ with bafetinib by $17 \%$ and LCB by $21 \%$ compared with DMSOtreated APP mice (Fig. 6c). There was no significant difference in levels of phospho-tau (Ser396) between treatment groups (Fig. 6d). However, there was a significant reduction in total tau levels in both bafetinib- and LCB-treated APP mice compared with DMSO-treated APP mice, yet this did
A
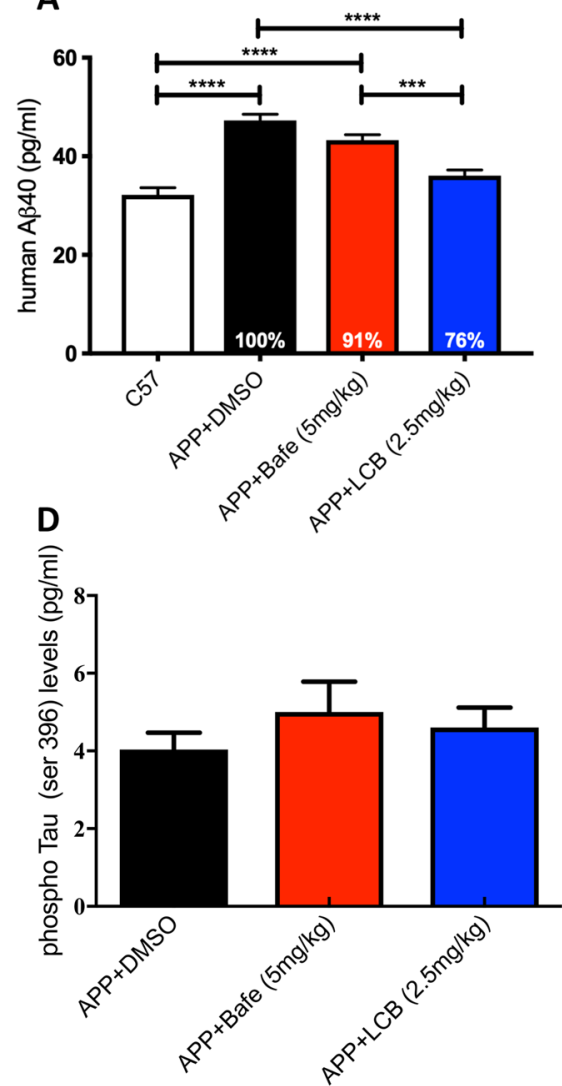

B
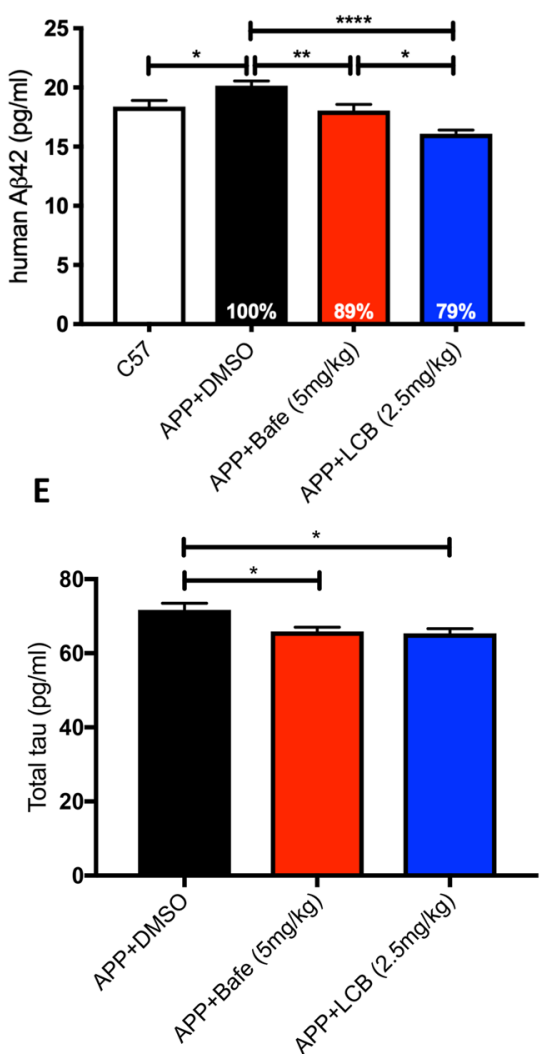

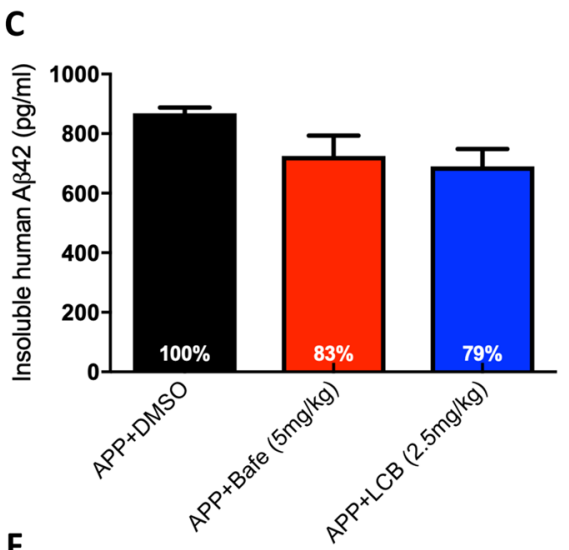

$\mathbf{F}$

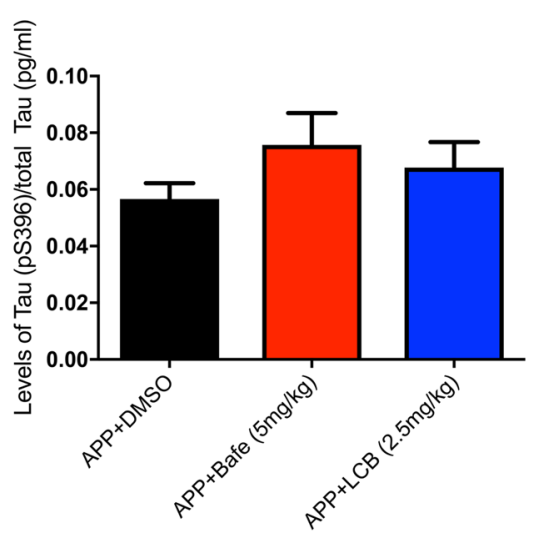

Fig. 6 Low dose of $2.5 \mathrm{mg} / \mathrm{kg}$ of LCB-03-011 and not $5 \mathrm{mg} / \mathrm{kg}$ of bafetinib ameliorates amyloid- $\beta$ and tau pathology in APP mice. Four- to seven-month-old APP mice were given an intraperitoneal (IP) injection with DMSO $(n=5), 5 \mathrm{mg} / \mathrm{kg}$ of bafetinib $(n=8)$, or $2.5 \mathrm{mg} / \mathrm{kg}$ of LCB $(n=8)$ for 21 consecutive days. Enzyme-linked immunosorbent assay (ELISA) concentrations $(\mathrm{pg} / \mathrm{mL}$ ) of a human
$\mathrm{A} \beta 42$ (pg/mL), b human $\mathrm{A} \beta 40$ (pg/mL), c insoluble human $\mathrm{A} \beta 42$ (pg/mL), $\mathbf{d}$ total tau (pg/mL), e phospho-tau (Ser396), and $\mathbf{f}$ ratio of phopsho-tau (Ser396) to total tau. Mean \pm standard error of the mean (SEM). Ordinary one-way analysis of variance (ANOVA), Tukey's multiple comparison test, ${ }^{*} p<0.05$; ${ }^{* *} p<0.01$; $* * * p<0.001$; $* * * * p<0.0001$ 


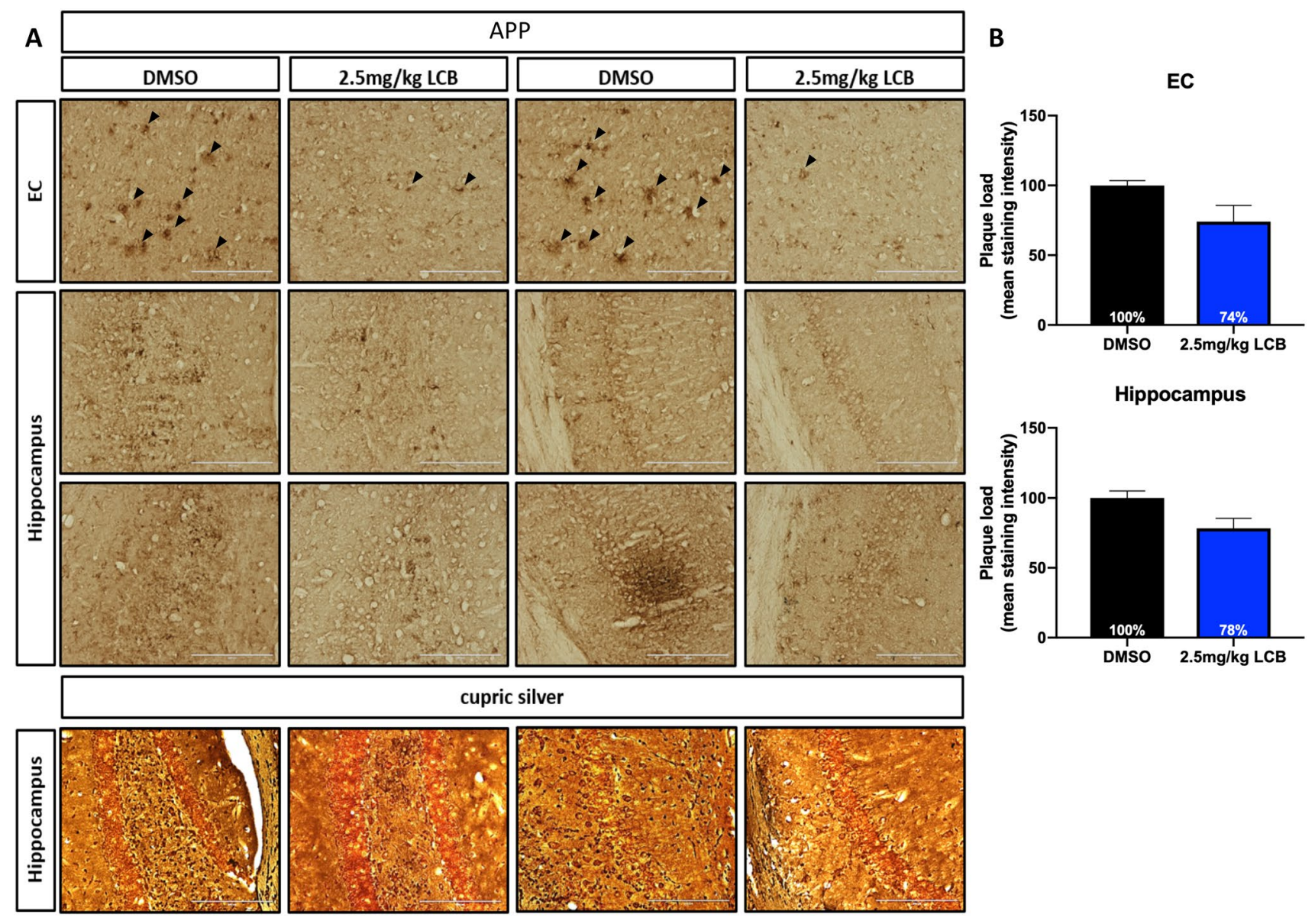

Fig. 7 Low dose of $2.5 \mathrm{mg} / \mathrm{kg}$ of LCB reduces plaque load in APP mice. Four- to seven-month-old APP mice given an intraperitoneal (IP) injection with dimethyl sulfoxide [DMSO] $(n=2)$ or $2.5 \mathrm{mg} / \mathrm{kg}$ of LCB $(n=4)$ for 21 consecutive days were used for immunohistological analysis. Immunohistochemistry staining of $20-\mu \mathrm{M}$-thick mouse brain sections shows a decreased amyloid- $\beta$ (A $\beta$ ) plaques via

not result in any significant changes when assessing the ratio of phosphorylated tau to total tau (Fig. 6e, f).

We further examined the plaque burden and cell number in the LCB-treated mice compared to DMSO APP mice via $6 \mathrm{E} 10$ antibodies to detect $\mathrm{A} \beta$ plaques and cupric silver stain to determine the cell number (Fig. 7). We probed for $\mathrm{A} \beta$ plaques in the entorhinal cortex (Fig. 7a, top row) where black arrows indicate examples of $\mathrm{A} \beta$ plaques. $\mathrm{LCB}$ $2.5 \mathrm{mg} / \mathrm{kg}$ reduced the plaque burden in the entorhinal cortex and the hippocampus compared with DMSO-treated mice (Fig. 7a). Quantification of plaque load via the mean staining intensity indicate a $26 \%$ and $22 \%$ reduction in plaque load in the entorhinal cortex and hippocampus, respectively, compared with DMSO (Fig. 7b). LCB reduced the number of cells that took up the silver stain, which suggests a higher number of viable cells in the hippocampus compared with DMSO-treated mice (Fig. 7a).
6E10 antibodies in the entorhinal cortex (EC) (top) and hippocampus (middle) and the cell number via cupric silver staining (bottom). b Plaque loads in the EC (top) and hippocampus (bottom) were quantified with a non-specific background correction using Image J. Data are presented as mean \pm standard error of the mean (SEM)

\section{Discussion}

The results indicate that effective TKIs in models of neurodegeneration display a complex relationship between target selectivity, levels of brain concentration, and CNS bioavailability (Fig. 8). Our data demonstrate differential effects of TKIs on the level of neurotoxic protein clearance using similar drug doses $(5-10 \mathrm{mg} / \mathrm{kg}$ ), route of administration (IP), and duration of treatment ( 3 weeks) in the same models of $\mathrm{AD}$ and PD. The CNS bioavailability of TKIs, including nilotinib, bosutinib, bafetinib, radotinib, and LCB was similar and indicates that these agents are completely washed out of the brain after 4-5 h of administration. The short bioavailability and low doses (compared to cancer models) of these TKIs provide a strategy to facilitate autophagic clearance for a short time, thus reducing the risk of prolonged activation of autophagy and self-cannibalization of neurons. Our data show that the selective Abl/DDR/PDGFR inhibitor, 


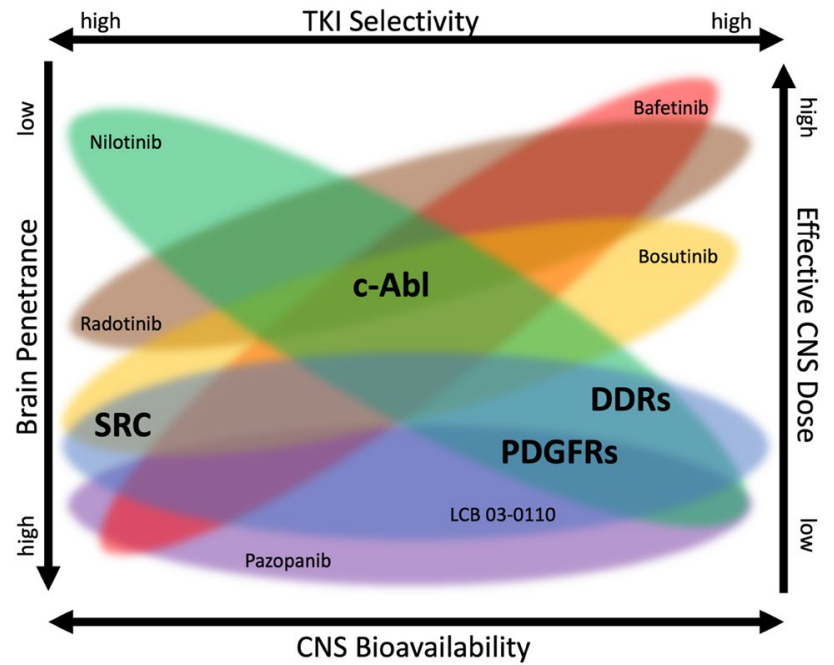

Fig. 8 Multi-kinase abelson (Abl)/discoidin domain receptor (DDR)/ Src inhibition suggests optimal effects for tyrosine kinase inhibitors (TKIs) in models of neurodegeneration. Kinetics and dynamics profiling of TKIs in animal models of neurodegeneration shows that selective Abl/DDR/platelet-derived growth factor receptor (PDGRF) inhibitor nilotinib has low central nervous system (CNS) penetrance and is effective at low-to-medium doses. The highly selective Abl inhibitor bafetinib has high CNS penetrance and may be partially effective at high doses. The highly selective Abl inhibitor radotinib has medium-to-high CNS penetrance and may be partially effective at high doses. The highly selective $\mathrm{Abl} / \mathrm{Src}$ inhibitor bosutinib has medium-to-high CNS penetrance and is highly effective at low doses. The highly selective PDGFR inhibitor pazopanib has high brain penetrance and is effective at low doses. The highly selective DDR/Src inhibitor LCB has high CNS penetrance and is highly effective at low doses

nilotinib has low CNS penetrance but is effective at low-tomedium doses (Fig. 8). Interestingly, when comparing the brain penetrance, using the ratio of brain-to-plasma levels, the data indicate that nilotinib has the lowest penetrance at $1 \%$. However, even with the low brain concentration, nilotinib has been shown by us and others to significantly reduce neurotoxic proteins, regulate immunity, and prevent neuronal loss in multiple models of proteinopathies [3-5, 29, 34-37]. The highly selective Abl/Src inhibitor bosutinib has medium/high CNS penetrance (5\%) compared to other TKIs and is highly effective at low doses $(5 \mathrm{mg} / \mathrm{kg})$ in models of neurodegeneration. Bosutinib is an Abl-Src inhibitor and is used clinically at a dose of $600-800 \mathrm{mg}$ daily $(80-100 \mathrm{mg} /$ $\mathrm{kg}$ in mice) to treat chronic myelogenous leukemia with minimal side effects. We previously reported that bosutinib is efficacious at reducing toxic proteins and improving cognitive and motor functions in models of neurodegeneration $[3,4,29,55]$. A range of $1-10 \mathrm{mg} / \mathrm{kg}$ is effective at reducing neurodegenerative pathologies, including $\alpha$-syn, tau $/ \mathrm{p}$-tau, and $A \beta_{42}$, and reducing inflammation in several animal models of NDs [3, 35, 37, 48].
Collectively, the data indicate that the efficacy of nilotinib and bosutinib may be co-mediated by Abl and Src. Targeting PDGFRs with pazopanib, a dual inhibitor of vascular endothelial growth factor receptors and PDGFRs, also reduced tau and $A \beta$ levels in the same models we studied in the current work [56], suggesting that nilotinib selectivity to PDGFRs (Table 1) may also play a role in producing an effective multi-kinase inhibition effect despite its low CNS level.

The selective Abl inhibitor bafetinib has the highest CNS penetrance ability (12\%) and may be effective at reducing $\mathrm{A} \beta$ levels in $\mathrm{AD}$ models at a high concentration. However, bafetinib failed to alter the level of $\alpha$-syn in transgenic PD models and affect dopamine metabolism using the same IP dose compared to either nilotinib or bosutinib, albeit bafetinib was reported to alter autophagy [57]. The halfmaximal inhibitory concentration $\left(\mathrm{IC}_{50}\right.$ ) of bafetinib to $\mathrm{Abl}$ is $62 \mathrm{nM}$ and $56 \mathrm{nM}$ to PDGFR $\alpha[58,59]$ with no affinity to PDGFR $\beta$ [42]. Bafetinib (INNO-406) development was aimed at extending the susceptibility spectrum of mutations to TKIs and increasing selectivity towards $\mathrm{Abl}$ to reduce clinical adverse reactions during treatment, e.g., cardiovascular and metabolic toxicities of nilotinib [60]. However, it is very important to mention that in the context of neurodegeneration, TKs are not mutated and the $\mathrm{IC}_{50}$ required to inhibit wild-type TKs that are upregulated in $\mathrm{AD}$ and $\mathrm{PD}$ brains may be significantly different from the $\mathrm{IC}_{50}$ reported in cancer studies and will depend on the type of assay performed, i.e., enzymatic activity, cell proliferation, and inhibition in mutated cell lines.

Previous studies showed that $10 \mathrm{mg} / \mathrm{kg}$ of bafetinib given to $\mathrm{C} 57$ mice for 1 week before MPTP treatment $(4 \times 20 \mathrm{mg} /$ $\mathrm{kg}$ IP, every $2 \mathrm{~h}$ ) and then for 1 week after MPTP treatment decreased the loss of striatal dopamine and protected substantia nigra neurons [51]. However, these experiments in MPTP models were not performed in an animal model that shows over-expression of toxic proteins, reminiscent of NDs. Furthermore, evaluation of another highly selective Abl inhibitor, radotinib, shows good CNS penetrance (5\%) and may be partially effective at high doses $(10 \mathrm{mg} / \mathrm{kg} \mathrm{IP})$ at reducing the levels of $\mathrm{A} \beta$ in $\mathrm{AD}$ mice. Previous studies showed that oral administration of three different doses (3, 5 , and $30 \mathrm{mg} / \mathrm{kg}$ ) of radotinib and $30 \mathrm{mg} / \mathrm{kg}$ of nilotinib, once a day for 5 months inhibits pre-formed fibril-induced Abl activation and reduces $\alpha$-syn pathology in vitro and in vivo [12]. These results were reported from longer treatment paradigms (5-6 months) in pre-formed fibril models and our experiments were performed in transgenic models where no surgery was performed to affect the concentration of CNS drugs and mice were treated for a significantly shorter time period. These data suggest that targeting Abl alone as a therapeutic strategy in neurodegeneration may be 
less effective than multi-kinase inhibition of $\mathrm{Abl}$ and DDRs or Abl and Src.

The highly selective DDR/Src inhibitor LCB has high CNS penetrance (12\%) and is very effective at low doses (Fig. 8). The display of this inverse dose dependency by LCB (Fig. 5) is intriguing, but may underscore the efficaciousness of a low brain concentration of nilotinib to result in large amelioration of neurodegenerative pathologies as previously reported. We suspect that this pharmacological property of LCB may be owing to the effect of the drug at multiple targets, especially at high concentrations, suggesting that multi-target engagement abrogates LCB action and may result in more off-target effects within the CNS. Therefore, the low dosage of LCB results in CNS drug concentrations that allow for very precise engagement of DDRs and Src alone. It is possible that a balance between drug concentrations in the CNS and target engagement is necessary and is best achieved at these lower concentrations, leading to more specific binding affinity and potent inhibition of DDRs and Src.

We previously demonstrated that shRNA knockdown of DDRs results in degradation of toxic proteins in in-vivo and in-vitro models of neurodegeneration [2]. Nilotinib and LCB are inhibitors of DDRs [53, 61]. Discoidin domain receptors are collagen-binding receptor TKs that have been implicated in a number of fundamental biological processes ranging from growth and development to immunoregulation [62]. Nilotinib inhibits DDR1 $\left(\mathrm{IC}_{50} 43 \mathrm{nM}\right)$ and DDR2 $\left(\mathrm{IC}_{50} 0.5 \mathrm{nM}\right)$ with high potency [63] and with an $\mathrm{IC}_{50}$ even lower than that of Abl. Taken together, the data from nilotinib, bafetinib, radotinib, and LCB, which is effective at reducing neurotoxic protein levels at the lowest concentration $(1.25-2.5 \mathrm{mg} / \mathrm{kg})$, suggest that DDRs are potentially more optimal targets for TKIs in neurodegeneration. LCB has the highest level of brain penetration (12\%) and displays maximum benefits in terms of the CNS availability:efficacy ratio. LCB also shares a strong property with bosutinib as an inhibitor of Src TKs [53]. Activation of Src kinases potentially exacerbates neurodegenerative pathology as previous findings suggest that prion proteins and $A \beta$ impair endocytosis and protein degradation [64], while Src inhibition attenuates microgliosis and reduces inflammation [65]. These findings are consistent with the observed effects of LCB [53] and bosutinib in several neurodegeneration models [3, 4, 29, 48, 55]. Bafetinib, nilotinib, and radotinib do not appear to inhibit Src [66].

Future studies will include examining other routes of administration of these TKIs. Repeated IP administration of DMSO may be unfavorable because of the toxicity of DMSO; therefore, an oral formulation and determination of the CNS TKI concentration via oral administration of these TKIs may be a likely follow-up study. Furthermore, additional studies on LCB with comparisons to nilotinib and bosutinib are necessary to fully dissect the individual contributions of the individual TKs to potential TKI therapies for neurodegeneration.

\section{Conclusions}

Taken together, our results suggest that Abl inhibition alone is suboptimal for treating neurodegenerative proteinopathies, despite the evidence of the effects of Abl on autophagy in neurodegeneration. Instead, our data indicate that the optimal target is the combination of Abl, DDRs, Src, and possibly PDGFR $\alpha / \beta$. Widespread inflammation and accumulation of activated microglia are features observed in NDs $[67,68]$. Evidence suggests that DDRs regulate myeloid-derived glial cells [16-19]. Discoidin domain receptor 1 has been shown to attenuate inflammation in models of atherosclerosis, renal disorder, and lung fibrosis [69-72]. Discoidin domain receptor 1 is also reported to upregulate matrix metallopeptidase 9 [17]. Upregulation of matrix metallopeptidase 9 leads to an impaired BBB [73-75]. Further, knockdown of DDR1 and DDR2 decreases BBB permeability [76]. The PDGFRs $\alpha / \beta$ are TKs that play an important role in neurodegeneration [43] and they regulate BBB pericytes [44-46]. Src, Btk, and Syk family kinases have been suggested as promising targets in the development of anti-inflammatory agents [77]. Therefore, multi-target TK inhibition may facilitate autophagic clearance of neurotoxic proteins, prevent degradation of the $\mathrm{BBB}$, regulate brain immunity, and provide a potentially protective mechanism in NDs.

Author contributions CM conceived the project, designed the study, and wrote the manuscript. $\mathrm{AF}$ and $\mathrm{MH}$ performed the experiments and wrote the manuscript. AF, AM, MH, RW, XG, TK, and XL performed the experiments. AF and MH analyzed the data. All authors read and approved the final manuscript.

\section{Compliance with Ethical Standards}

Funding These studies were supported by funding from Georgetown University to Charbel Moussa.

Conflict of interest Charbel Moussa is listed as an inventor of an issued US and international patent to use tyrosine kinase inhibitors to treat neurodegenerative diseases. No other author has any conflict of interest.

Ethics approval All mouse studies were conducted in full compliance with the recommendations of the Georgetown University Animal Care and Use Committee under protocol 2016-1194.

Data availability All data generated or analyzed during this study are included in this article (and the Electronic Supplementary Material).

Open Access This article is distributed under the terms of the Creative Commons Attribution-NonCommercial 4.0 International License 
(http://creativecommons.org/licenses/by-nc/4.0/), which permits any noncommercial use, distribution, and reproduction in any medium, provided you give appropriate credit to the original author(s) and the source, provide a link to the Creative Commons license, and indicate if changes were made.

\section{References}

1. Schlatterer SD, Acker CM, Davies P. c-Abl in neurodegenerative disease. J Mol Neurosci. 2011;45(3):445-52.

2. Hebron M, Peyton M, Liu X, Gao X, Wang R, Lonskaya I, et al. Discoidin domain receptor inhibition reduces neuropathology and attenuates inflammation in neurodegeneration models. J Neuroimmunol. 2017;311:1-9.

3. Lonskaya I, Hebron ML, Desforges NM, Franjie A, Moussa CE. Tyrosine kinase inhibition increases functional parkin-Beclin-1 interaction and enhances amyloid clearance and cognitive performance. EMBO Mol Med. 2013;5(8):1247-62.

4. Hebron ML, Lonskaya I, Moussa CE. Tyrosine kinase inhibition facilitates autophagic SNCA/alpha-synuclein clearance. Autophagy. 2013;9(8):1249-50.

5. Hebron ML, Lonskaya I, Moussa CE. Nilotinib reverses loss of dopamine neurons and improves motor behavior via autophagic degradation of alpha-synuclein in Parkinson's disease models. Hum Mol Genet. 2013;22(16):3315-28.

6. Jing Z, Caltagarone J, Bowser R. Altered subcellular distribution of c-Abl in Alzheimer's disease. J Alzheimers Dis. 2009;17(2):409-22.

7. Ko HS, Lee Y, Shin JH, Karuppagounder SS, Gadad BS, Koleske AJ, et al. Phosphorylation by the c-Abl protein tyrosine kinase inhibits parkin's ubiquitination and protective function. Proc Natl Acad Sci USA. 2010;107(38):16691-6.

8. Imam SZ, Zhou Q, Yamamoto A, Valente AJ, Ali SF, Bains M, et al. Novel regulation of parkin function through c-Abl-mediated tyrosine phosphorylation: implications for Parkinson's disease. J Neurosci. 2011;31(1):157-63.

9. Schlatterer SD, Tremblay MA, Acker CM, Davies P. Neuronal c-Abl overexpression leads to neuronal loss and neuroinflammation in the mouse forebrain. J Alzheimers Dis. 2011;25(1):119-33.

10. Brahmachari S, Ge P, Lee SH, Kim D, Karuppagounder SS, Kumar M, et al. Activation of tyrosine kinase c-Abl contributes to alpha-synuclein-induced neurodegeneration. J Clin Investig. 2016;126(8):2970-88.

11. Tremblay MA, Acker CM, Davies P. Tau phosphorylated at tyrosine 394 is found in Alzheimer's disease tangles and can be a product of the Abl-related kinase. Arg J Alzheimers Dis. 2010;19(2):721-33.

12. Lee S, Kim S, Park YJ, Yun SP, Kwon SH, Kim D, et al. The c-Abl inhibitor, radotinib $\mathrm{HCl}$, is neuroprotective in a preclinical Parkinson's disease mouse model. Hum Mol Genet. 2018;27(13):2344-56

13. Welch PJ, Wang JY. A C-terminal protein-binding domain in the retinoblastoma protein regulates nuclear c-Abl tyrosine kinase in the cell cycle. Cell. 1993;75(4):779-90.

14. Van Etten RA, Jackson PK, Baltimore D, Sanders MC, Matsudaira $\mathrm{PT}$, Janmey PA. The $\mathrm{COOH}$ terminus of the c-Abl tyrosine kinase contains distinct $\mathrm{F}$ - and $\mathrm{G}$-actin binding domains with bundling activity. J Cell Biol. 1994;124(3):325-40.

15. Wang JY. Regulation of cell death by the Abl tyrosine kinase. Oncogene. 2000;19(49):5643-50.

16. Vogel WF, Abdulhussein R, Ford CE. Sensing extracellular matrix: an update on discoidin domain receptor function. Cell Signal. 2006;18(8):1108-16.
17. Roig B, Franco-Pons N, Martorell L, Tomas J, Vogel WF, Vilella E. Expression of the tyrosine kinase discoidin domain receptor 1 (DDR1) in human central nervous system myelin. Brain Res. 2010;1336:22-9.

18. Seo MC, Kim S, Kim SH, Zheng LT, Park EK, Lee WH, et al. Discoidin domain receptor 1 mediates collagen-induced inflammatory activation of microglia in culture. J Neurosci Res. 2008;86(5):1087-95.

19. Kamohara H, Yamashiro S, Galligan C, Yoshimura T. Discoidin domain receptor 1 isoform-a (DDR1alpha) promotes migration of leukocytes in three-dimensional collagen lattices. FASEB J. 2001;15(14):2724-6.

20. Fowler AJ, Moussa CE. Activating autophagy as a therapeutic strategy for Parkinson's disease. CNS Drugs. 2018;32(1):1-11.

21. Boland B, Kumar A, Lee S, Platt FM, Wegiel J, Yu WH, et al. Autophagy induction and autophagosome clearance in neurons: relationship to autophagic pathology in Alzheimer's disease. J Neurosci. 2008;28(27):6926-37.

22. Webb JL, Ravikumar B, Atkins J, Skepper JN, Rubinsztein DC. Alpha-synuclein is degraded by both autophagy and the proteasome. J Biol Chem. 2003;278(27):25009-13.

23. Stefanis L, Larsen KE, Rideout HJ, Sulzer D, Greene LA. Expression of A53T mutant but not wild-type alpha-synuclein in PC12 cells induces alterations of the ubiquitin-dependent degradation system, loss of dopamine release, and autophagic cell death. J Neurosci. 2001;21(24):9549-60.

24. Sabatini DM. mTOR and cancer: insights into a complex relationship. Nat Rev Cancer. 2006;6(9):729-34.

25. Ravikumar B, Duden R, Rubinsztein DC. Aggregate-prone proteins with polyglutamine and polyalanine expansions are degraded by autophagy. Hum Mol Genet. 2002;11(9):1107-17.

26. Nixon RA, Wegiel J, Kumar A, Yu WH, Peterhoff C, Cataldo A, et al. Extensive involvement of autophagy in Alzheimer disease: an immuno-electron microscopy study. J Neuropathol Exp Neurol. 2005;64(2):113-22.

27. Kegel KB, Kim M, Sapp E, McIntyre C, Castano JG, Aronin $\mathrm{N}$, et al. Huntingtin expression stimulates endosomal-lysosomal activity, endosome tubulation, and autophagy. J Neurosci. 2000;20(19):7268-78.

28. Yang Y, Fukui K, Koike T, Zheng X. Induction of autophagy in neurite degeneration of mouse superior cervical ganglion neurons. Eur J Neurosci. 2007;26(10):2979-88.

29. Lonskaya I, Hebron ML, Algarzae NK, Desforges N, Moussa CE. Decreased parkin solubility is associated with impairment of autophagy in the nigrostriatum of sporadic Parkinson's disease. Neuroscience. 2013;232:90-105.

30. Lonskaya I, Shekoyan AR, Hebron ML, Desforges N, Algarzae NK, Moussa CE. Diminished parkin solubility and co-localization with intraneuronal amyloid-beta are associated with autophagic defects in Alzheimer's disease. J Alzheimers Dis. 2013;33(1):231-47.

31. O'Brien SG, Guilhot F, Larson RA, Gathmann I, Baccarani $\mathrm{M}$, Cervantes $\mathrm{F}$, et al. Imatinib compared with interferon and low-dose cytarabine for newly diagnosed chronic-phase chronic myeloid leukemia. N Engl J Med. 2003;348(11):994-1004.

32. Druker BJ, Guilhot F, O’Brien SG, Gathmann I, Kantarjian H, Gattermann N, et al. Five-year follow-up of patients receiving imatinib for chronic myeloid leukemia. N Engl J Med. 2006;355(23):2408-17.

33. Musumeci F, Schenone S, Brullo C, Botta M. An update on dual Src/Abl inhibitors. Fut Med Chem. 2012;4(6):799-822.

34. Kantarjian HM, Giles F, Gattermann N, Bhalla K, Alimena G, Palandri F, et al. Nilotinib (formerly AMN107), a highly selective BCR-ABL tyrosine kinase inhibitor, is effective in patients with Philadelphia chromosome-positive chronic myelogenous 
leukemia in chronic phase following imatinib resistance and intolerance. Blood. 2007;110(10):3540-6.

35. Moussa CE. Parkin is dispensable for mitochondrial function, but its ubiquitin ligase activity is critical for macroautophagy and neurotransmitters: therapeutic potential beyond Parkinson's disease. Neurodegener Dis. 2015;15(5):259-70.

36. Lonskaya I, Hebron ML, Selby ST, Turner RS, Moussa CE. Nilotinib and bosutinib modulate pre-plaque alterations of blood immune markers and neuro-inflammation in Alzheimer's disease models. Neuroscience. 2015;304:316-27.

37. Lonskaya I, Hebron ML, Desforges NM, Schachter JB, Moussa CE. Nilotinib-induced autophagic changes increase endogenous parkin level and ubiquitination, leading to amyloid clearance. J Mol Med (Berl). 2014;92(4):373-86.

38. Lonskaya I, Desforges NM, Hebron ML, Moussa CE. Ubiquitination increases parkin activity to promote autophagic alphasynuclein clearance. PLoS One. 2013;8(12):e83914.

39. Hebron ML, Lonskaya I, Olopade P, Selby ST, Pagan F, Moussa CE. Tyrosine kinase inhibition regulates early systemic immune changes and modulates the neuroimmune response in alphasynucleinopathy. J Clin Cell Immunol. 2014;5:259.

40. Pagan F, Hebron M, Valadez EH, Torres-Yaghi Y, Huang $X$, Mills RR, et al. Nilotinib effects in Parkinson's disease and dementia with Lewy bodies. J Parkinsons Dis. 2016;6(3):503-17.

41. Bantscheff M, Eberhard D, Abraham Y, Bastuck S, Boesche M, Hobson S, et al. Quantitative chemical proteomics reveals mechanisms of action of clinical ABL kinase inhibitors. Nat Biotechnol. 2007;25(9):1035-44.

42. Rix U, Hantschel O, Durnberger G, Remsing Rix LL, Planyavsky M, Fernbach NV, et al. Chemical proteomic profiles of the BCR-ABL inhibitors imatinib, nilotinib, and dasatinib reveal novel kinase and nonkinase targets. Blood. 2007;110(12):4055-63.

43. Weisberg E, Wright RD, Jiang J, Ray A, Moreno D, Manley PW, et al. Effects of PKC412, nilotinib, and imatinib against GIST-associated PDGFRA mutants with differential imatinib sensitivity. Gastroenterology. 2006;131(6):1734-42.

44. Rossari F, Minutolo F, Orciuolo E. Past, present, and future of Bcr-Abl inhibitors: from chemical development to clinical efficacy. J Hematol Oncol. 2018;11(1):84.

45. Kisler K, Nelson AR, Rege SV, Ramanathan A, Wang Y, Ahuja A, et al. Pericyte degeneration leads to neurovascular uncoupling and limits oxygen supply to brain. Nat Neurosci. 2017;20(3):406-16.

46. Bell RD, Winkler EA, Sagare AP, Singh I, LaRue B, Deane R, et al. Pericytes control key neurovascular functions and neuronal phenotype in the adult brain and during brain aging. Neuron. 2010;68(3):409-27.

47. Kang SH, Li Y, Fukaya M, Lorenzini I, Cleveland DW, Ostrow LW, et al. Degeneration and impaired regeneration of gray matter oligodendrocytes in amyotrophic lateral sclerosis. Nat Neurosci. 2013;16(5):571-9.

48. Massella A, D'Intino G, Fernandez M, Sivilia S, Lorenzini L, Giatti S, et al. Gender effect on neurodegeneration and myelin markers in an animal model for multiple sclerosis. BMC Neurosci. 2012;13:12.

49. Papadopoulos N, Lennartsson J. The PDGF/PDGFR pathway as a drug target. Mol Asp Med. 2018;62:75-88.

50. Hebron ML, Javidnia M, Moussa CE. Tau clearance improves astrocytic function and brain glutamate-glutamine cycle. J Neurol Sci. 2018;391:90-9.

51. Remsing Rix LL, Rix U, Colinge J, Hantschel O, Bennett KL, Stranzl T, et al. Global target profile of the kinase inhibitor bosutinib in primary chronic myeloid leukemia cells. Leukemia. 2009;23(3):477-85.
52. Boschelli DH, Ye F, Wang YD, Dutia M, Johnson SL, Wu B, et al. Optimization of 4-phenylamino-3-quinolinecarbonitriles as potent inhibitors of Src kinase activity. J Med Chem. 2001;44(23):3965-77.

53. Imam SZ, Trickler W, Kimura S, Binienda ZK, Paule MG, Slikker W Jr, et al. Neuroprotective efficacy of a new brain-penetrating C-Abl inhibitor in a murine Parkinson's disease model. PLoS One. 2013;8(5):e65129.

54. Lee S, Kim S, Park YJ, Yun SP, Kwon S-H, Kim D, et al. The c-Abl inhibitor, radotinib $\mathrm{HCl}$ is neuroprotective in a preclinical Parkinson's disease mouse model. Hum Mol Genet. 2018;27(13):2344-56.

55. Sun X, Phan TN, Jung SH, Kim SY, Cho JU, Lee H, et al. LCB 03-0110, a novel pan-discoidin domain receptor/c-Src family tyrosine kinase inhibitor, suppresses scar formation by inhibiting fibroblast and macrophage activation. J Pharmacol Exp Ther. 2012;340(3):510-9.

56. Giasson BI, Duda JE, Quinn SM, Zhang B, Trojanowski JQ, Lee VM. Neuronal alpha-synucleinopathy with severe movement disorder in mice expressing A53T human alpha-synuclein. Neuron. 2002;34(4):521-33.

57. Wenqiang C, Lonskaya I, Hebron ML, Ibrahim Z, Olszewski RT, Neale JH, et al. Parkin-mediated reduction of nuclear and soluble TDP-43 reverses behavioral decline in symptomatic mice. Hum Mol Genet. 2014;23(18):4960-9.

58. Javidnia M, Hebron ML, Xin Y, Kinney NG, Moussa CE. Pazopanib reduces phosphorylated tau levels and alters astrocytes in a mouse model of tauopathy. J Alzheimers Dis. 2017;60(2):461-81.

59. Kamitsuji Y, Kuroda J, Kimura S, Toyokuni S, Watanabe K, Ashihara E, et al. The Bcr-Abl kinase inhibitor INNO-406 induces autophagy and different modes of cell death execution in Bcr-Ablpositive leukemias. Cell Death Differ. 2008;15(11):1712-22.

60. Kimura S, Naito H, Segawa H, Kuroda J, Yuasa T, Sato K, et al. NS-187, a potent and selective dual Bcr-Abl/Lyn tyrosine kinase inhibitor, is a novel agent for imatinib-resistant leukemia. Blood. 2005;106(12):3948-54.

61. Pan J, Quintas-Cardama A, Manshouri T, Cortes J, Kantarjian $\mathrm{H}$, Verstovsek S. Sensitivity of human cells bearing oncogenic mutant kit isoforms to the novel tyrosine kinase inhibitor INNO406. Cancer Sci. 2007;98(8):1223-5.

62. Steegmann JL, Baccarani M, Breccia M, Casado LF, GarciaGutierrez V, Hochhaus A, et al. European LeukemiaNet recommendations for the management and avoidance of adverse events of treatment in chronic myeloid leukaemia. Leukemia. 2016;30(8):1648-71.

63. Kothiwale S, Borza CM, Lowe EW Jr, Pozzi A, Meiler J. Discoidin domain receptor 1 (DDR1) kinase as target for structure-based drug discovery. Drug Discov Today. 2015;20(2):255-61.

64. Iwai LK, Luczynski MT, Huang PH. Discoidin domain receptors: a proteomic portrait. Cell Mol Life Sci. 2014;71(17):3269-79.

65. Kim HG, Tan L, Weisberg EL, Liu F, Canning P, Choi HG, et al. Discovery of a potent and selective DDR1 receptor tyrosine kinase inhibitor. ACS Chem Biol. 2013;8(10):2145-50.

66. Sempou E, Biasini E, Pinzon-Olejua A, Harris DA, Malaga-Trillo E. Activation of zebrafish Src family kinases by the prion protein is an amyloid-beta-sensitive signal that prevents the endocytosis and degradation of E-cadherin/beta-catenin complexes in vivo. Mol Neurodegener. 2016;11:18.

67. Manocha GD, Puig KL, Austin SA, Seyb K, Glicksman MA, Combs CK. Characterization of novel Src family kinase inhibitors to attenuate microgliosis. PLoS One. 2015;10(7):e0132604.

68. Rix U, Remsing Rix LL, Terker AS, Fernbach NV, Hantschel O, Planyavsky M, et al. A comprehensive target selectivity survey of the BCR-ABL kinase inhibitor INNO-406 by kinase profiling and chemical proteomics in chronic myeloid leukemia cells. Leukemia. 2010;24(1):44-50. 
69. Croisier E, Moran LB, Dexter DT, Pearce RK, Graeber MB. Microglial inflammation in the parkinsonian substantia nigra: relationship to alpha-synuclein deposition. J Neuroinflammation. 2005;2:14.

70. Akiyama H, Barger S, Barnum S, Bradt B, Bauer J, Cole GM, et al. Inflammation and Alzheimer's disease. Neurobiol Aging. 2000;21(3):383-421.

71. Franco C, Hou G, Ahmad PJ, Fu EY, Koh L, Vogel WF, et al. Discoidin domain receptor 1 (ddr1) deletion decreases atherosclerosis by accelerating matrix accumulation and reducing inflammation in low-density lipoprotein receptor-deficient mice. Circ Res. 2008;102(10):1202-11.

72. Avivi-Green C, Singal M, Vogel WF. Discoidin domain receptor 1-deficient mice are resistant to bleomycin-induced lung fibrosis. Am J Respir Crit Care Med. 2006;174(4):420-7.

73. Flamant M, Placier S, Rodenas A, Curat CA, Vogel WF, Chatziantoniou $\mathrm{C}$, et al. Discoidin domain receptor 1 null mice are protected against hypertension-induced renal disease. J Am Soc Nephrol. 2006;17(12):3374-81.

74. Franco C, Britto K, Wong E, Hou G, Zhu SN, Chen M, et al. Discoidin domain receptor 1 on bone marrow-derived cells promotes macrophage accumulation during atherogenesis. Circ Res. 2009;105(11):1141-8.

75. Gao H, Chakraborty G, Zhang Z, Akalay I, Gadiya M, Gao $\mathrm{Y}$, et al. Multi-organ site metastatic reactivation mediated by non-canonical discoidin domain receptor 1 signaling. Cell. 2016;166(1):47-62.
76. Lakhan SE, Kirchgessner A, Tepper D, Leonard A. Matrix metalloproteinases and blood-brain barrier disruption in acute ischemic stroke. Front Neurol. 2013;4:32.

77. Wu Y, Wang YP, Guo P, Ye XH, Wang J, Yuan SY, et al. A lipoxin A4 analog ameliorates blood-brain barrier dysfunction and reduces MMP-9 expression in a rat model of focal cerebral ischemia-reperfusion injury. J Mol Neurosci. 2012;46(3):483-91.

78. Zhu M, Xing D, Lu Z, Fan Y, Hou W, Dong H, et al. DDR1 may play a key role in destruction of the blood-brain barrier after cerebral ischemia-reperfusion. Neurosci Res. 2015;96:14-9.

79. Bradshaw JM. The Src, Syk, and Tec family kinases: distinct types of molecular switches. Cell Signal. 2010;22(8):1175-84.

80. Manley PW, Drueckes P, Fendrich G, Furet P, Liebetanz J, Martiny-Baron G, et al. Extended kinase profile and properties of the protein kinase inhibitor nilotinib. Biochim Biophys Acta. 2010;1804(3):445-53.

81. Selleckchem. Bafetinib (INNO-406) (NS-187). 2013. https://www. selleckchem.com/products/Bafetinib.html. Accessed 14 Mar 2019.

82. Eskazan AE, Keskin D. Radotinib and its clinical potential in chronic-phase chronic myeloid leukemia patients: an update. Ther Adv Hematol. 2017;8(9):237-43.

83. Kim SH, Menon H, Jootar S, Saikia T, Kwak JY, Sohn SK, et al Efficacy and safety of radotinib in chronic phase chronic myeloid leukemia patients with resistance or intolerance to BCR-ABL1 tyrosine kinase inhibitors. Haematologica. 2014;99(7):1191-6. 